\title{
Composição florística e fitofisionomia de remanescentes disjuntos de Cerrado nos Campos Gerais, PR, Brasil - limite austral do bioma
}

\author{
Lia Maris Orth Ritter ${ }^{1,4}$, Milton Cezar Ribeiro ${ }^{2} \&$ Rosemeri Segecin Moro ${ }^{3}$ \\ ${ }^{1}$ Departamento de Ciências Florestais, Escola Superior de Agricultura Luiz de Queiroz, \\ Universidade de São Paulo - USP, Av. Padua Dias, 11, Agronomia, CEP 13418-900, Piracicaba, SP, Brasil \\ ${ }^{2}$ Departamento de Ecologia, Universidade de São Paulo - USP, Rua do Matão, Travessa 14, \\ Cidade Universitária, CEP 05508-900, São Paulo, SP, Brasil \\ ${ }^{3}$ Departamento de Biologia Geral, Universidade Estadual de Ponta Grossa - UEPG, \\ Av. Carlos Cavalcanti, 4748, CEP 84030-000, Uvaranas, PR, Brasil \\ ${ }^{4}$ Autor para correspondência: Lia Maris Orth Ritter, e-mail: Imritter@esalq.usp.br
}

RITTER, L.M.O., RIBEIRO, M.C. \& MORO, R.S. Floristic composition and phytophysiognomies of Cerrado disjunct remnants in Campos Gerais, PR, Brazil - Southern boundary of the biome. Biota Neotrop. 10(3): http://www.biotaneotropica.org.br/v10n3/en/abstract?inventory+bn04010032010.

\begin{abstract}
The cerrado (Brazilian savannah) has its Southern limits of occurrence in the Campos Gerais region in the State of Paraná, through small disjunction patches with great affinities with the Northern savannah formations of São Paulo and the Central Plateau of Brazil. They are mostly on private lands, under strong pressure from agribusiness and have been hitherto little studied. A floristic and phytophysiognomical analysis of 30 remnants in different municipalities was carried out, reaching a total of 1,782 determined taxa, being Asteraceae the richest family (256), followed by Fabaceae (207), Poaceae (183), Myrtaceae (72) and Melastomataceae (54). There is a geomorphological and latitudinal gradient on the distribution of physiognomies: cerrado stricto sensu (50\%) and cerradão (13\%) are distributed mainly in the sandstone plateaus in the north region, while cerrado rupestre $(17 \%)$ and grassland with cerrado facies $(20 \%)$ are most frequent in the river valleys cliffs in the South. These remnants present floristic similarity with the core area of the Biome, and could be considered marginal areas of the geographical range of several taxa, sharing typical species of the Southern Province. Thus the whole area would be more correctly named savannah instead of steppe. The austral phytocoenosis of Ponta Grossa, a possible endemism centre with great richness, is biogeographically isolated from the other cerrado patches.
\end{abstract}

Keywords: savannah, Campos Gerais, phytogeography.

RITTER, L.M.O., RIBEIRO, M.C. \& MORO, R.S. Composição florística e fitofisionomia de remanescentes disjuntos de Cerrado nos Campos Gerais, PR, Brasil - limite austral do bioma. Biota Neotrop. 10(3): http:// www.biotaneotropica.org.br/v10n3/pt/abstract?inventory+bn04010032010.

Resumo: O cerrado possui seu limite austral de ocorrência nos Campos Gerais do Paraná onde, na forma de pequenos fragmentos disjuntos, tem grande afinidade com as formações savânicas de São Paulo e do Planalto Central do Brasil. Encontra-se, na sua maior parte, em propriedades particulares, sob forte pressão da agropecuária, tendo sido até então pouco estudado. Foram realizadas análises florísticas e fitofisionômicas de 30 remanescentes de cerrado em seis municípios, com determinação de um total de 1.782 táxons. Asteraceae foi a família com maior riqueza de espécies (256), seguida por Fabaceae (207), Poaceae (183), Myrtaceae (72) e Melastomataceae (54). Encontrou-se um gradiente latitudinal e geomorfológico na distribuição das fisionomias: cerrado stricto sensu $(50 \%)$ e cerradão $(13 \%)$ distribuem-se nos planaltos areníticos ao norte da região; enquanto cerrado rupestre (17\%) e campo sujo com fácies de cerrado (20\%) estão mais representados nas porções meridionais, nos relevos escarpados dos vales dos rios. Os remanescentes mostraram similaridade florística com áreas core do Bioma e podem ser consideradas áreas marginais da amplitude geográfica de muitos táxons, compartilhando espécies típicas, características da Província Sulina. Portanto, estas áreas campestres seriam melhor classificadas como savanas do que como estepes. A fitocenose mais austral em Ponta Grossa, com alta riqueza de espécies, encontra-se isolada biogeograficamente dos demais elementos do Bioma, constituindo um possível centro de endemismo.

Palavras-chave: cerrado, Campos Gerais, fitogeografia. 


\section{Introdução}

O Cerrado, no Brasil, é um complexo vegetacional composto por cinco tipos fisionômicos distintos que abrange desde fisionomias campestres até arborescentes mais densas, com aspecto florestal, e fitotipias ecotonais intermediárias (Coutinho 1978, Oliveira Filho \& Ratter 2002). Para Walter (2006, p. 10), "Savana é uma paisagem estruturalmente intermediária entre floresta e campo"... "paisagem com um estrato graminoso contínuo (ou descontínuo), contendo árvores ou arbustos espalhados".

Sendo o segundo maior Bioma em extensão, após a Amazônia (Oliveira-Filho \& Ratter 2002), já chegou a ocupar aproximadamente $1.900 .000 \mathrm{~km}^{2}$ do espaço geográfico brasileiro, mas nos últimos 30 anos as regiões de Cerrado tem sofrido rápidas transformações pela expansão da agri-silvicultura. De acordo com Myers et al. (2000), apenas $20 \%$ da área original permanece como vegetação primária - uma situação preocupante devido ao alto índice de endemismo, que alcança cerca de $44 \%$ de um total de 10.000 espécies. Por esta razão, o Cerrado foi incluído na lista dos hotspots mundiais de biodiversidade (Mittermeier et al. 1999) e, para Machado et al. (2004), o avanço antrópico poderá ser a causa de sua supressão até meados do ano de 2030.

Sua área nuclear de ocorrência são os planaltos do Brasil Central, chapadões interiores dos Estados de Minas Gerais, Mato Grosso do Sul, Mato Grosso, Goiás, Tocantins e Bahia, além de manchas expressivas nos Estados de Rondônia, Piauí e São Paulo, e em algumas áreas pontuais do Paraná (Instituto... 2004). Ratter et al. (2003) distribuem o Cerrado no Brasil em seis províncias florísticas: sulina, centro-oeste, central e sudeste, extremo-oeste, nordeste e disjunções amazônicas. Apesar da heterogeneidade natural, cinco províncias (excetua-se as disjunções amazônicas) compartilham as 25 espécies mais frequentes, as quais podem ser consideradas como espécies características que definem o Bioma.

Os remanescentes de cerrado nos Campos Gerais do Paraná também se acham sob forte pressão da expansão do agronegócio, sem terem sido ainda completamente documentados. Após a notificação de sua existência (Maack 1931, 1968, Hueck 1957, Klein 1979, Leite \& Klein 1990), surgem estudos sobre sua composição florística e estrutura (Takeda et al. 1996, Straube 1998, Uhlmann et al. 1997, 1998, Uhlmann 1995, 2003, von Linsingen et al. 2001, Hatschbach et al. 2005, Carmo 2006, von Linsingen et al. 2006, Cervi \& von Linsingen 2008, von Linsingen \& Cervi, 2008,) e ampliação de sua distribuição (Ritter et al. 2006, 2007a, b, Ritter \& Moro 2007, Ritter 2008).

Segundo Takeda et al. (1996) e Durigan et al. (2003), os componentes da associação florística dos campos cerrados nesta área correspondem a uma versão empobrecida do revestimento vegetal dos campos cerrados do Estado de São Paulo e do Planalto Central do Brasil. Passos (2003) lembra que a medida que se expande de sua área central de domínio para áreas periféricas, o Cerrado vai se tornando mais esparso, até que se torne escasso e, por fim, ausente. Para Uhlmann et al. (1998), von Linsingen et al. (2006), Carmo (2006) e Hatschbach et al. (2005), no entanto, há grande diversidade de espécies e elevado grau de endemismo no Cerrado conservado nos Campos Gerais.

Este trabalho atualiza a florística e a classificação fitofisionômica de fragmentos de Cerrado nos Campos Gerais do Paraná, ampliando os dados da literatura por expedições a campo, especialmente em sua distribuição mais austral, para estabelecimento dos limites da província sulina do Bioma.

\section{Material e Métodos}

Os Campos Gerais, ao longo da Cuesta da Escarpa Devoniana, apresentam-se como uma faixa de território de 11.761,41 km² com convexidade para noroeste (Melo et al. 2003). A região foi definida por Maack (1948) como uma unidade fitogeográfica compreendendo os campos limpos e campos cerrados naturais situados sobre o Segundo Planalto Paranaense.

Predominam as tipologias climáticas de Koeppen Cfa (subtropical com verões quentes e chuvas concentradas no verão) e Cfb (temperado, com verões frescos, sem estação seca definida). Os solos onde se observam mais comumente manchas de cerrado nos Campos Gerais são do tipo latossolos vermelho-amarelos e neossolos litólicos, mas também podem ocorrer em cambissolos e argissolos (Melo et al. 2003).

As fisionomias de cerrado consensualmente citadas (Henriques 2005) se baseiam num conjunto de formações vegetacionais dispostas de acordo com um crescente de biomassa: campo limpo, fisionomia estritamente graminóide, normalmente ocupando solos distróficos; campo sujo, onde ocorrem esparsos arbustos, com até $1 \%$ de cobertura, prevalecendo, contudo, espécies herbáceas; campo cerrado, composta por arbustos um pouco mais desenvolvidos, com cobertura de até $10 \%$, mas onde as herbáceas ainda são abundantes; cerrado sensu stricto, que passa a apresentar tanto indivíduos arbóreos quanto arbustivos mais desenvolvidos, com uma cobertura de dossel de 30-40\%; e o cerradão, fisionomia com aspecto florestal, com cobertura de dossel arbóreo de cerca de 30-60\% (Eiten 1972, 1977, 1983, Ferri 1977, Coutinho 1978, 1982, 1990, Ribeiro \& Walter 1998, Coutinho 2002). Henriques (2005) omite a fisionomia de campo sujo, enquanto Ribeiro \& Walter (1998) e Oliveira Filho \& Martins (1986) acrescentam também o cerrado rupestre. Este ocorre em solos rasos com presença de afloramentos de rocha, com cobertura de dossel variando de $5-20 \%$ e altura média de 2 a $4 \mathrm{~m}$. O estabelecimento de plantas arbóreas adaptadas a esse ambiente de solos rasos ocorre apenas quando estas encontram fendas entre as rochas (Reatto et al. 1998). O termo campo limpo é evitado por muitos autores para evitar confusões nomenclaturais com as estepes (Coutinho 1978), porquanto alguns preferem o termo campo sujo com fácies de cerrado ao se referir ao cerrado estritamente graminóide, com raros arbustos (Ritter et al. 2007b), juntando aí os conceitos de campo limpo e campo sujo citado por Henriques (2005).

Foram analisados florística e fitofisionomicamente 30 pontos de ocorrência de Cerrado (Figura 1), entre 2006 e 2008, através dos métodos de Avaliação Ecológica Rápida (Sayre et al., 2000) e Caminhamento (Filgueiras et al., 1994), para amostragem qualitativa de forma expedita. Esses pontos estavam distribuídos nos Municípios de Sengés, Jaguariaíva, Piraí do Sul, Tibagi, Carambeí e Ponta Grossa, ao longo da APA da Escarpa Devoniana, sob as coordenadas UTM (x1: 550.331; x2: 677.996) e (y1: 7.206.826; y2: 7.345.909). Nos fragmentos que apresentavam mais de uma fisionomia, foi considerada apenas aquela que revestia a maior parte de cada área, sendo visualmente a mais conspícua.

Todo material coletado foi herborizado seguindo recomendações de Fidalgo e Bononi (1984) e encontra-se no acervo do herbário da Universidade Estadual de Ponta Grossa (HUPG). A listagem florística complementou dados de literatura dos Parques Estaduais de Vila Velha, do Cerrado e Guartelá (Cervi et al. 2007, Uhlmann et al. 1995, Uhlmann et al. 1998, Uhlmann 2003, von Lisingen et al. 2006, Takeda et al. 1996, Carmo 2006). Os nomes válidos e sinonímias foram pesquisados no site do Missouri Botanical Garden (Mobot 2010), seguindo o Angiosperm Phylogeny Group (APG).

Para avaliar a similaridade florística entre as áreas utilizou-se análise estatística multivariada de agrupamento através do programa Statistica for Windows (StatSoft 1998), além de Análise de Componentes Principais - PCA (Ter Braak 1987), através da linguagem R (Ihaka \& Gentleman 1996). 


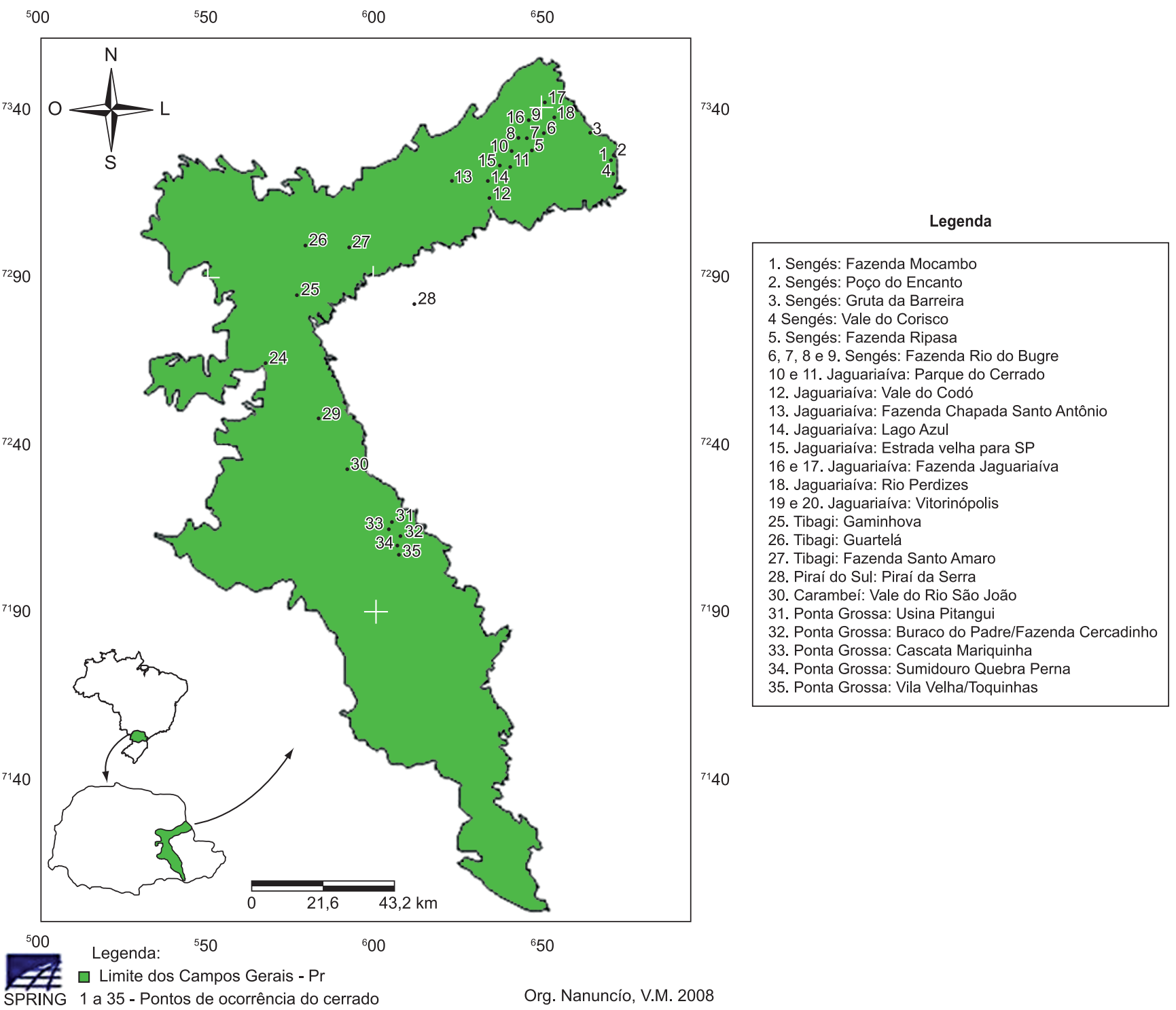

Figura 1. Delimitação dos Campos Gerais no Estado do Paraná e localização dos fragmentos de cerrado estudados.

Figure 1. Delimitation of Campos Gerais in Paraná State and the savannah fragments studied.

\section{Resultados e Discussão}

Os remanescentes pesquisados nos Campos Gerais foram classificados como campo sujo, cerrado stricto sensu, cerrado rupestre e cerradão (Figura 2). Em direção a maiores latitudes, até o limite austral de ocorrência (Ponta Grossa), há uma sucessão gradual de fisionomias, decrescente em biomassa, até campo sujo com fácies de cerrado. A maioria dos fragmentos compõe-se por cerrado stricto sensu (15 áreas), seguidas por seis áreas de campo sujo, cinco áreas de cerrado rupestre e apenas quatro áreas de cerradão, estas localizadas mais ao norte, nos municípios de Sengés e Jaguariaíva.

O Bioma Cerrado possui uma grande riqueza florística, com mais de 6.389 táxons nativos pertencentes a 6.062 espécies de fanerógamas (Mendonça et al. 1998, 2006), sendo muitos de distribuição restrita (Ratter et al. 2003). Este estudo registrou 1.782 táxons (Anexo 1), com 659 espécies arbustivo/arbóreas, 92 lianas e 1031 herbáceas, dentre as quais pelo menos seis espécies consideradas raras e ameaçadas em algum grau (Hatschbach \& Ziller 1995): na categoria "rara": Cayaponia espelina (Silva Manso) Cogn. (Curcubitaceae) e Byrsonima coccolobifolia Kunth (Malpighiaceae), na categoria "vulnerável": Caryocar brasiliense Camb. (Caryocaraceae) e Mimosa lanata Benth. (Fabaceae) e na categoria "em perigo de extinção", Diospyros hispida DC (Ebenaceae) e Pradosia brevipes Pierre (T.D.Penn) (Sapotaceae). Asteraceae é a família com maior riqueza de espécies (256), seguida por Fabaceae (207), Poaceae (183), Myrtaceae (72) e Melastomataceae (54).

Hatschbach et al. (2005) listam mais de 1.300 espécies para o Estado do Paraná, enquanto von Lisingen et al. (2006) apontam 458 espécies apenas para o Parque Estadual do Cerrado (Jaguariaíva, PR). Longhi-Wagner (2003) aponta para o Estado do Paraná o limite austral de 60 espécies de gramíneas predominantemente tropicais, muitas também de ocorrência nos Cerrados, evidenciando a importância do contingente florístico tropical na composição destas estepes. Igualmente para Fabaceae, Miotto \& Waechter (2003) 


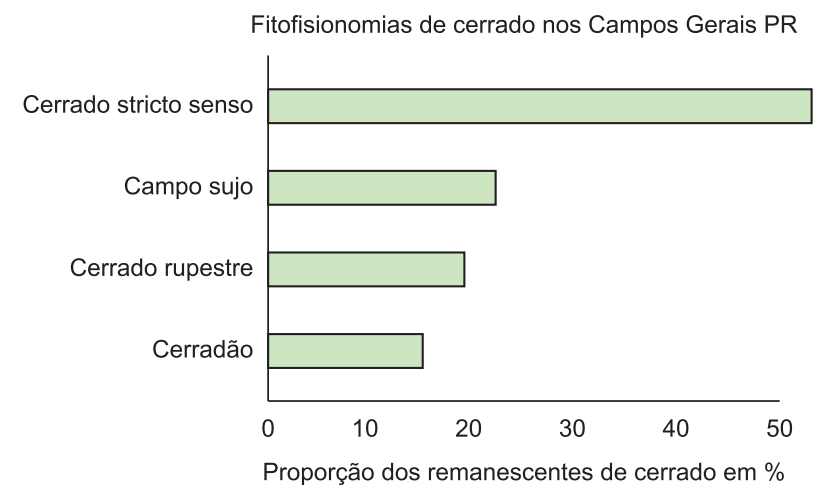

Figura 2. Proporção de fitofisionomias dos fragmentos de cerrado nos Campos Gerais, Estado do Paraná.

Figure 2. Proportion of phitophysiognomies of savannah remnants in Campos Gerais, Parana State.

apontam os campos paranaenses como limite austral de espécies tropicais. Waechter et al. (2003), levando em consideração Poaceae e Fabaceae, reforçam a idéia da província campestre paranaense em oposição à pampeana, num claro gradiente latitudinal de influência decrescente das espécies tropicais na composição florística estépica.

O cruzamento de dados florísticos referente à riqueza de famílias para 10 áreas de cerrado dos Campos Gerais (Figura 3) apontou que áreas em Ponta Grossa e Carambeí apresentam maior similaridade entre si, enquanto Tibagi e Guartelá formam um segundo grupo, estando mais próximos de Vila Velha. O Parque Estadual do Cerrado constitui um terceiro grupo à parte dos demais, sendo o mais diverso no nível de riqueza de famílias. Isto provavelmente está refletindo a diferença de esforços amostrais nestas áreas, uma vez que as unidades de conservação possuem listas florísticas mais completas do que os remanescentes em propriedades particulares, além de fragmentos com maior área contínua.

$\mathrm{Na}$ análise de componentes principais para a matriz de presença/ ausência de espécies (Figura 4), pode-se observar uma oposição entre os determinantes da composição florística dos Parques do Cerrado e do Guartelá em relação às áreas mais austrais (Piraí do Sul, Carambeí e Ponta Grossa). Analisando-se a similaridade floristica de espécies arbóreas típicas do Cerrado sulino (Bridgewater et al. 2004) e sua distribuição nas fitocenoses consideradas neste estudo (Tabela 1), numa perspectiva de gradiente latitudinal, percebe-se que dez táxons estão presentes em todas as fitocenoses; seis presentes apenas a partir do município de Tibagi (B e C); e três restritos à região de Jaguariaíva e Sengés $(\mathrm{C})$.

Observa-se que as áreas de Cerrado em Ponta Grossa (fitocenose A), todas de fitofisionomia de campo sujo com fácies de cerrado ou cerrado rupestre, compartilham onze espécies (44\%) com as formações savânicas sulinas: Annona coriacea Mart., Copaifera langsdorfii Desf., Caryocar brasiliense Camb., Plenckia populnea, Acosmium subelegans (Mohlenbr) Yakovlev, Casearia sylvestris Sw., Ocotea pulchella Mart., Lafoensia pacari A.St.-Hill., Byrsonima intermedia Juss., Roupala Montana Aubl. e Machaerium acutifolium Vogel.

Cervi et al. (2007), comparando a flora do Parque Estadual de Vila Velha com a do Bioma Cerrado (Mendonça et al. 1998), verificou que há cerca de $40 \%$ de espécies compartilhadas. Tratando-se somente de gramíneas, são cerca de $63 \%$ as espécies semelhantes entre essas áreas. Para este autor, o caráter savânico das áreas abertas destas regiões pertencem efetivamente ao domínio do Bioma Cerrado e, portanto, as formações campestres dos Campos Gerais deveriam ser mais corretamente denominadas como savana gramíneo lenhosa,

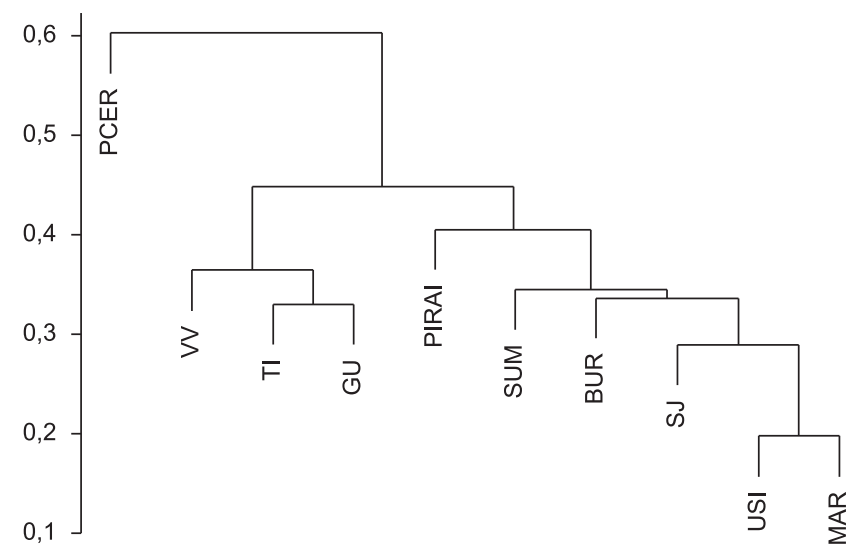

Figura 3. Análise de Agrupamento das áreas de cerrado com informação florística, utilizando dados de riqueza de famílias nos Campos Gerais, PR. Legenda: PCER- Parque Estadual do Cerrado; VV- Parque Estadual de Vila Velha; TI- Tibagi; GU- Parque Estadual do Guartelá; PIRAI- Piraí da Serra; SUM- Sumidouro do Quebra Perna; BUR- Buraco do Padre; SJ- Vale do Rio São João; USI- Usina Pitangui; MAR- Cachoeira Mariquinha.

Figure 3. Cluster Analysis of savannah areas with floristic information, using data from family richness in Campos Gerais, PR. Legend: PCER- Parque Estadual do Cerrado; VV- Parque Estadual de Vila Velha; TI- Tibagi; GU- Parque Estadual do Guartelá; PIRAI- Piraí da Serra; SUM- Sumidouro do Quebra Perna; BUR- Buraco do Padre; SJ- Vale do Rio São João; USI- Usina Pitangui; MAR- Cachoeira Mariquinha.

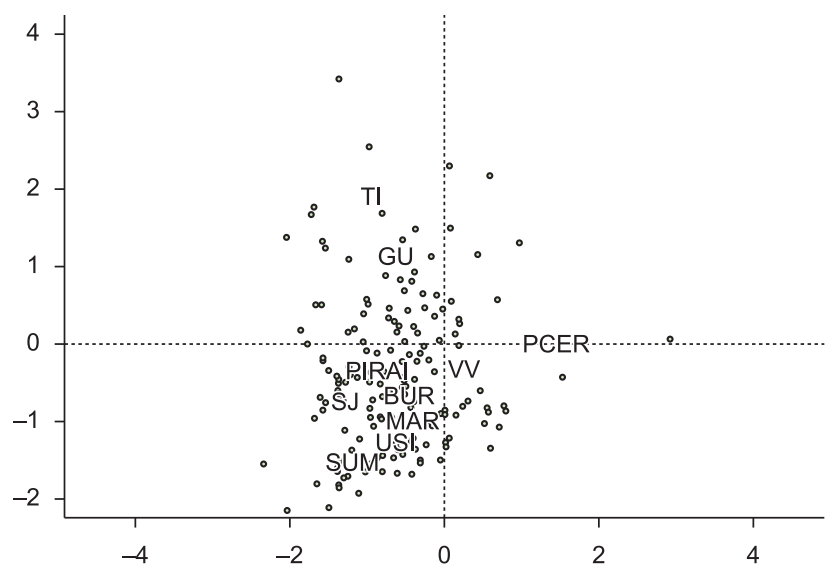

Figura 4. Análise de componentes principais considerando presença e ausência de espécies nas áreas de estudo nos Campo Gerais, PR. As siglas são as mesmas utilizadas na Figura 3.

Figure 4. Principal components analysis considering the presence and absence of species in the studied areas in Campos Gerais, PR. Abbreviations are the same used in Figure 3.

contrariamente ao IBGE (Veloso et al. 1991), que as classifica como estepe gramíneo lenhosa. O mapa de Biomas do IBGE (Instituto... 2004) corrige até certo ponto esta distorção ao expandir o Bioma Cerrado até o Norte dos Campos Gerais, porém os dados desta análise corroboram a proposição de Cervi et al. (2007) na ampliação dos limites de ocorrência de savana.

Os fragmentos de Tibagi, Piraí do Sul e Carambeí (fitocenose B), com fitofisionomias variando de cerrado sensu stricto a cerrado rupestre, compartilham 16 espécies típicas com a Província Sulina (64\%). Os remanescentes conservados nos municípios de Jaguariaíva e Sengés (fitocenose C), com fitofisionomias do tipo cerrado sensu stricto, cerradão e eventualmente campo cerrado, compartilham 20 espécies típicas com a Província Sulina (80\%). 
Tabela 1. Ocorrência das espécies arbóreas típicas da Província Sulina de Cerrado sensu Bridgewater et al. (2004) nos fragmentos analisados. A: Ponta Grossa; B: Tibagi, Piraí do Sul e Carambeí; C: Sengés e Jaguariaíva.

Table 1. Occurrence of typical arboreous species of South Province (sensu Bridgewater et al., 2004) in the Cerrado patches analyzed.

\begin{tabular}{|c|c|c|c|c|}
\hline Espécie & Família & $\mathbf{A}$ & B & $\mathbf{C}$ \\
\hline Lafoensia pacari & Lythraceae & $\mathrm{x}$ & $\mathrm{x}$ & $\mathrm{x}$ \\
\hline Annona coriacea & Annonaceae & $\mathrm{x}$ & $\mathrm{x}$ & $\mathrm{x}$ \\
\hline Caryocar brasiliense & Caryocaraceae & $\mathrm{x}$ & $\mathrm{x}$ & $\mathrm{x}$ \\
\hline Plenckia populnea & Celastraceae & $\mathrm{x}$ & $\mathrm{x}$ & $\mathrm{x}$ \\
\hline Acosmium subelegans & Fabaceae & $\mathrm{x}$ & $\mathrm{x}$ & $\mathrm{x}$ \\
\hline Copaifera langsdorffii & Fabaceae & $\mathrm{x}$ & $\mathrm{x}$ & $\mathrm{x}$ \\
\hline Casearia sylvestris & Salicaceae & $\mathrm{x}$ & $\mathrm{x}$ & $\mathrm{x}$ \\
\hline Ocotea pulchella & Lauraceae & $\mathrm{x}$ & $\mathrm{x}$ & $\mathrm{x}$ \\
\hline Byrsonima intermedia & Malpighiaceae & $\mathrm{x}$ & $\mathrm{x}$ & $\mathrm{x}$ \\
\hline Roupala montana & Proteaceae & $\mathrm{x}$ & $\mathrm{x}$ & $\mathrm{x}$ \\
\hline Erythroxylum suberosum & Erythroxylaceae & - & $\mathrm{x}$ & $\mathrm{x}$ \\
\hline Tabebuia ochracea & Bignoniaceae & - & $\mathrm{x}$ & $\mathrm{x}$ \\
\hline Dalbergia miscolobium & Fabaceae & - & $\mathrm{x}$ & $\mathrm{x}$ \\
\hline Byrsonima coccolobifolia & Malpighiaceae & - & $\mathrm{x}$ & $\mathrm{x}$ \\
\hline Ouratea spectabilis & Ochnaceae & - & $\mathrm{X}$ & $\mathrm{X}$ \\
\hline Didymopanax vinosum & Araliaceae & - & - & $\mathrm{x}$ \\
\hline Qualea grandiflora & Vochysiaceae & - & - & $\mathrm{x}$ \\
\hline Machaerium acutifolium & Fabaceae & $\mathrm{x}$ & - & $\mathrm{x}$ \\
\hline Piptocarpha rotundifolia & Asteraceae & - & - & - \\
\hline Couepia grandiflora & Chrysobalanaceae & - & $\mathrm{x}$ & $\mathrm{x}$ \\
\hline Qualea multiflora & Vochysiaceae & - & - & $\mathrm{x}$ \\
\hline Xylopia aromatica & Annonaceae & - & - & - \\
\hline Eugenia aurata & Myrtaceae & - & - & - \\
\hline Eriotheca gracilipes & Malvaceae & - & - & - \\
\hline Dimorphandra mollis & Fabaceae & - & - & - \\
\hline
\end{tabular}

\section{Conclusões}

As disjunções de Cerrado nos Campos Gerais possuem similaridade florística com áreas core do Bioma e podem ser consideradas áreas marginais da amplitude geográfica de muitos táxons típicos deste tipo de vegetação, compartilhando espécies características da Província Sulina de Cerrado. Embora exista um gradiente latitudinal de decréscimo de biomassa e similaridade entre fitocenoses, devido a maior riqueza de espécies e biodiversidade, uma barreira fitogeográfica é observada entre as fitocenoses do Parque Estadual do Guartelá e seu entorno, e a do Parque Estadual de Vila Velha e entorno.

As disjunções da fitocenose de Vila Velha exibem apenas fitofisionomias campestres compatíveis com o campo sujo com fácies de cerrado e cerrado rupestre. Floristicamente, exibem atributos qualitativos suficientes para serem consideradas fitocenoses de Cerrado. As análises realizadas apontam a necessidade de revisão do conceito de estepe gramíneo-lenhosa para a porção austral dos Campos Gerais.

\section{Referências Bibliográficas}

BRIDGEWATER, S., RATTER, J.A. \& RIBEIRO, J.F. 2004. Biogeographic patterns, b-diversity and dominance in the cerrado biome of Brazil. Biodivers. Conserv. 13:2295-2318.
CARMO, M.R.B. 2006. Caracterização fitofisionômica do Parque Estadual do Guartelá, município de Tibagi, Estado do Paraná. Tese de Doutorado. Universidade Estadual Paulista Julio de Mesquita Filho, Rio Claro.

CERVI, A.C. \& VON LINSINGEN, L. 2008. Sinopse taxonômica das Passifloraceae Juss. no complexo de cerrado (savana) no estado do Paraná - Brasil. Iheringia, Sér. Bot. 63(1):145-157.

CERVI, A.C., VON LINSINGEN, L., HATSCHBACH, G. \& RIBAS, O.S. 2007. A vegetação do Parque Estadual de Vila Velha, município de Ponta Grossa, Paraná, Brasil. Bol. Mus. Bot. Mun. 69:1-52.

COUTINHO, L.M. 1978. O conceito de cerrado. Rev. Bras. Bot. 1:17-23.

COUTINHO, L.M. 1982. Ecological effects of fire in Brazilian Cerrado. In Ecology of Tropical Savannas (B.J. Huntley \& B.H. Wakler, eds.). Springer-Verlag, Berlin, p.273-291.

COUTINHO, L.M. 1990. Fire in the ecology of the Brazilian cerrado. In Fire in the tropical biota. (J.G Goldammer, ed.). Springer-Verlag, Berlin, p.81-105.

COUTINHO, L.M. 2002. O bioma cerrado. In Eugen Warming e o cerrado brasileiro: um século depois (A.L. Klein, org.). Ed. UNESP, São Paulo, p.77-91.

DURIGAN, G., RATTER, J.A., BRIDGEWATER, S., SIQUEIRA, M.F. \& FRANCO, G.A.D.C. 2003. Padrões fitogeográficos do cerrado paulista sob uma perspectiva regional. Hoehnea 30(1):217-241.

EITEN, G. 1972. The cerrado vegetation of Brazil. Bot. Rev. 38:201-341.

EITEN, G. 1977. Delimitação do conceito cerrado. Arq. Jard. Bot. 21:125-134.

EITEN, G. 1983. Classificação da Vegetação do Brasil. Conselho Nacional de Desenvolvimento Científico e Tecnológico, Brasília, 305p.

FERRI, M.G. 1977. Ecologia do Cerrado. In IV Simpósio sobre o Cerrado: bases para utilização agropecuária. EDUSP, São Paulo, p.15-36.

FIDALGO, O. \& BONONI, V.L. 1984. Técnicas de coleta, preservação e herborização de material botânico. Instituto de Botânica, São Paulo. Manual 4.

FILGUEIRAS, T.S., NOGUEIRA, P.E., BROCHADO, A.L. \& GUALLA II, G.F. 1994. Caminhamento: um método expedito para levantamentos florísticos qualitativos. Cad. Geocienc. 12:39-43.

HATSCHBACH, G. \& ZILLER, S. 1995. Lista vermelha de plantas ameaçadas de extinção no Estado do Paraná. SEMA/GTZ, Curitiba.

HATSCHBACH, G., VON LINSINGEN, L., UHLMANN, A., CERVI, A.C. \& SONEHARA, J.S. 2005. Levantamento florístico do cerrado paranaense e vegetação associada. Bol. Mus. Bot. Mun. Curitiba 67:1-40.

HENRIQUES, R.P.B. 2005. Influência da história, solo e fogo na distribuição e dinâmica das fitofisionomias no bioma do Cerrado. In Cerrado: Ecologia, Biodiversidade e Conservação (J.C. Souza Silva \& J.M. Felfili, eds.). Ministério do Meio Ambiente, Brasília, p.73-92.

HUECK, K. 1957. Sobre a origem dos campos cerrados no Brasil e algumas novas observações no seu limite meridional. Rev. Bras. Geogr. 19(1):67-82.

IHAKA, R. \& GENTLEMAN, R. 1996. R language for data analysis and graphics. J. Comput. Graph. Stat. 5:299-314.

Instituto Brasileiro de Geografia e Estatística - IBGE. 2004. Mapa de Biomas do Brasil.www.ibge.gov.br/mapas (último acesso em 10/07/2009).

KLEIN, R. 1979. Contribuição ao conhecimento da vegetação das partes do $1^{\circ}$ e $2^{\circ}$ planaltos paranaenses. In 30 Congresso Brasileiro de Botânica. Campo Grande, p.200-201.

LEITE, P.F. \& KLEIN, R.M. 1990. Vegetação. In Geografia do Brasil. IBGE, Rio de Janeiro, p.113-150.

LONGHI-WAGNER, H.M. 2003. Diversidade florística dos campos sulbrasileiros: Poaceae. In 54 Congresso Nacional de Botânica. SBB, Belém, p.117-120.

MAACK, R. 1931. Urwald und Savanne im Landschaftsbild des Staates Paraná. Zeitsch. Gesselsh. Erdk. 3-4:95-116.

MAACK, R. 1948. Notas preliminares sobre clima, solos e vegetação do Estado do Paraná. Curitiba, Arq. Biol. Tecnol. 2:102-200. 
MAACK, R. 1968. Geografia Física do Paraná. Livraria José Olímpio, Rio de Janeiro, 450p.

MACHADO, R.B., RAMOS NETO, M.B., PEREIRA, P.G.P., CALDAS, E.F., GONÇALVES, D.A., SANTOS, N.S., TABOR, K. \& STEININGER, M. 2004. Estimativas de perda da área do Cerrado brasileiro. Conservação Internacional, Brasília, 23p. Relatório Técnico.

MELO, M.S. Caracterização do Patrimônio Natural dos Campos Gerais do Paraná. UEPG, Ponta Grossa. Projeto financiado pela Fundação Araucária e CNPq. www.uepg.br/natural.htm. (último acesso em 25/08/2008).

MENDONÇA, R.C., FELFILI, J.M., WALTER, B.M.T., SILVA JUNIOR, M.C., REZENDE, A.V., FILGUEIRAS, T.S. \& NOGUEIRA, P.H. 2006. Flora vascular do Bioma Cerrado. Embrapa Cerrados, Brasília.

MENDONÇA, R.C., FELFILI, J.M., WALTER, B.M.T., SILVA JÚNIOR, M.C., REZENDE, A.V., FILGUEIRAS, T.S. \& NOGUEIRA, P.E. 1998. Flora vascular do cerrado. In Cerrado: ambiente e Flora (S. Sano \& S.P. Almeida, Eds.). Embrapa Cerrados, Planaltina, p.289-556.

MIOTTO, S.T.S. \& WAECHTER, J.L. 2003. Diversidade florística dos campos sul-brasileiros: Fabaceae. In 54 Congresso Nacional de Botânica. SBB, Belém, p.121-124.

MISSOURI BOTANICAL GARDEN - MOBOT. 2010. Tropicos. www. tropicos.org (último acesso em 01/02/2010).

MITTERMEIER, R.A., MYERS, N., GIL, P.R. \& MITTERMEIER, C.G. 1999. Hotspots: earth's biologically richest and most endangered terrestrial ecoregions. CEMEX, Mexico City, 431p.

MYERS, N., MITTERMEIER, R.A., MITTERMEIER, C.G., FONSECA, G.A.B. \& KENT, J. 2000. Biodiversity hotspots for conservation priorities. Nature 403(6772):853-858.

OLIVEIRA-FILHO, A.T. \& MARTINS, F.R. 1986. Distribuição, caracterização e composição florística das formações vegetais da região da Salgadeira, na Chapada dos Guimarães (MT). Rev. Bras. Bot. 9:207-223.

OLIVEIRA-FILHO, A.T. \& RATTER, J.A. 2002. Vegetation physionomies and wood flora of the Cerrado Biome. In The Cerrados of Brazil: ecology and natural history of a neotropical savanna. R.J. Oliveira \& P.S. Marquis, eds.). Columbia University Press, New York, p.91-120.

PASSOS, M.M. 2003. Biogeografia e Paisagem. Maringá, 264p.

RATTER, J.A., BRIDGEWATER, S. \& RIBEIRO, J.F. 2003. Analysis of the floristic composition of the Brazilian Cerrado vegetation. III: comparison of the woody vagetation of 376 areas. EJB 60(1):57-109.

REATTO, A., CORREIA, J.R. \& SPERA, S.T. 1998. Solos do bioma cerrado: aspectos pedológicos. In Cerrado: ambiente e flora (S.M. Sano \& S.P. Almeida, eds). Embrapa, Planaltina, p.47-86.

RIBEIRO, J.F. \& WALTER, B.M.T. 1998. Fitofisionomias do bioma cerrado. In Cerrado: ambiente e flora. (S.M. Sano \& S.P. Almeida, eds.) EMBRAPA, Planaltina, p.89-166.

RITTER, L.M.O. \& MORO, R.S. 2007. Similaridade florística entre as disjunções de cerrado na bacia do Alto Tibagi, PR. Terr@ Plural $1(2): 85-98$.

RITTER, L.M.O. 2008. Composição florística e aspectos físicos do cerrado nos Campos Gerais, Paraná. Dissertação de Mestrado. Universidade Estadual de Ponta Grossa, Paraná.

RITTER, L.M.O., DE ALMEIDA, C.G., NANUNCIO, V.M. \& MORO, R.S. 2007a. Caracterização florística e fitofisionômica de um fragmento de cerrado em Carambeí, na região dos Campos Gerais, PR. In 2 Simpósio Paranaense de Pós Graduação em Geografia. Londrina.

RITTER, L.M.O., ALMEIDA, C.G. \& Moro, R.S. 2007b. Caracterização fitofisionômica dos fragmentos campestres com fácies de cerrado em Ponta Grossa PR. Rev. Bras. Biociênc. 5(2):192-194.
RITTER, L.M.O.; ALMEIDA, C.G. \& MORO, R.S. 2006. Mapeamento preliminar das ocorrências de Cerrado nos Campos Gerais, PR. In Simpósio Estadual da Pós Graduação em Geografia do Paraná. UEM, Maringá, p.587-596.

SAYRE, R., ROCA, E., SEDAGHATKISH, G., YOUNG, B., KEEL, S., ROCA, R. \& SHEPPARD, S. 2000. Natureza em foco: Avaliação Ecológica Rápida. The Nature Conservancy, Arlington, 182p.

STATSOFT. 1998. Statistica for Windows 6.0. Tulsa.

STRAUBE, F.C. 1998. O Cerrado no Paraná: ocorrência original e subsídios para sua conservação. Cad. Biodivers. 1(2):12-24.

TAKEDA, I.J.M., MORO, R,.S. \& KACZMARECH, R. 1996. Análise florística de um encrave de cerrado no Parque do Guartelá, Tibagi, PR. Publicatio 2(1):21-31.

TER BRAAK, C.J.F. 1987. Ordination. In Data Analysis in Community and Landscape Ecology (R.H.G Jongman, C.J.F Ter Braak \& O.F.R Van Tongeren, eds.). University Press, Oxford, p.91-173.

UHLMANN, A. 1995. Análise fitossociológica de três categorias fitofisionômicas no Parque Estadual do Cerrado, Jaguariaíva, PR. Dissertação de Mestrado, Universidade Federal do Paraná, Curitiba.

UHLMANN, A. 2003. Análise estrutural de duas áreas de vegetação savânica (cerrado) sob influência de gradientes ambientais complexos. Tese de Doutorado, Universidade de Campinas, Campinas.

UHLMANN, A., CURCIO., FRANKLIN, G. \& SILVA, S. M. 1997. Relações entre a distribuição das categorias fitofisionômicas e padrões geomórficos e pedológicos em uma área de savana (cerrado) no estado do Paraná, Brasil. Arq. Biol. Tecn. 40(2):473-484.

UHLMANN, A., GALVÃO, F. \& SILVA, S.M. 1998. Análise da estrutura de duas unidades fitofisionômicas de savana (cerrado) no sul do Brasil. Acta. Bot. Bras. 12(3):231-247.

VELOSO, H.P., RANGEL FILHO, A.L.R. \& LIMA, J.C.A. 1991. Classificação da vegetação brasileira, adaptada a um sistema universal. Departamento de Recursos Naturais e Estudos Ambientais, IBGE, Rio de Janeiro, 123p.

VON LINSINGEN, L. \& CERVI, A.C. 2008. A Familia Combretaceae R. Brown nas formações de cerrado do Estado do Paraná, Brasil. Pesquisas 59:211-222.

VON LINSINGEN, L., HATSCHBACH, G., UHLMANN, A., SILVA, S.M., CERVI, A.C. \& SONEHARA, J.S. 2001. Levantamento florístico das áreas disjuntas de cerrado e vegetação associada do Estado do Paraná. In Encontro Regional de Botânicos do Paraná e Santa Catarina. Regional Paraná Santa Catarina da Sociedade Botânica do Brasil, Curitiba, p.122.

VON LINSINGEN, L., SONEHARA, J.S., UHLMANN, A. \& CERVI, A.C. 2006. Composição florística do Parque Estadual do Cerrado de Jaguariaíva, Paraná, Brasil. Acta Biol. Par. 35(3-4):197-232.

WAECHTER, J.L., LONGHI-WAGNER, H.M. \& MIOTTO, S.T.S. 2003. Relações florísticas nos campos sul-brasileiros. In 54 Congresso Nacional de Botânica. SBB, Belém, p.130-133.

WALTER, B.M.T. 2006. Fitofisionomias do bioma Cerrado: síntese terminológica e relações florísticas. Tese de Doutorado, Universidade de Brasília, Brasília Brasília.

Recebido em 21/04/2010 Versão reformulada recebida em 01/09/2010 Publicado em 20/09/2010 


\section{Anexo}

Anexo 1. Espécies de cerrado encontradas em Campos Gerais, Paraná, Sul do Brasil.

Attachment 1. Savannah species found in Campos Gerais, Parana State, South Brazil.

\begin{tabular}{|c|c|}
\hline Família & Espécie \\
\hline ACANTHACEAE & Dyschoriste hygrophyllodes (Nees) Kuntze \\
\hline ACANTHACEAE & Ruellia dissitifolia (Nees) Lindau \\
\hline ACANTHACEAE & Ruellia geminiflora Kunth \\
\hline ACANTHACEAE & Ruellia multifolia (Nees) Lindau \\
\hline ACANTHACEAE & Stenandrium neesianum Lindau \\
\hline ALSTROEMERIACEAE & Alstroemeria apertiflora Baker \\
\hline AMARANTHACEAE & Alternanthera brasiliana $(\mathrm{L})$ Kuntze \\
\hline AMARANTHACEAE & Alternanthera rufa (Mart.) D. Dietr. \\
\hline AMARANTHACEAE & Chenopodium retusum (Moq.) Moq. \\
\hline AMARANTHACEAE & Gomphrena celosioides Mart. \\
\hline AMARANTHACEAE & Gomphrena gnaphaloides (L. f.) Vahl \\
\hline AMARANTHACEAE & Gomphrena graminea Moq \\
\hline AMARANTHACEAE & Gomphrena officinalis var. macrocephala (St. Hil.) J.C. Siqueira \\
\hline AMARANTHACEAE & Gomphrena paranensis R.E. Fries \\
\hline AMARANTHACEAE & Gomphrena regeliana Seub. \\
\hline AMARANTHACEAE & Gomphrena virgata Mart \\
\hline AMARANTHACEAE & Pfaffia glabrata Mart. \\
\hline AMARANTHACEAE & Pfaffia gnaphaloides (L.f.) Mart \\
\hline AMARANTHACEAE & Pfaffia helichrysoides (Mart.) Kuntze \\
\hline AMARANTHACEAE & Pfaffia jubata Mart. \\
\hline AMARANTHACEAE & Pfaffia sericea (Moq.) Kunth \\
\hline AMARANTHACEAE & Pfaffia tuberosa (Moq. Ex DC) Hicken \\
\hline AMARYLLIDACEAE & Amaryllis iguazuana Ravenna \\
\hline AMARYLLIDACEAE & Habranthus coeruleus (Griseb.) Taub. \\
\hline AMARYLLIDACEAE & Hippeastrum psittacinum Herb \\
\hline AMARYLLIDACEAE & Nothoscordum inodorum (Airton) G. Nicholson \\
\hline AMARYLLIDACEAE & Nothoscordum luteomajus Ravenna \\
\hline AMARYLLIDACEAE & Nothoscordum sengesianum Ravenna \\
\hline ANACARDIACEAE & Anacardium humile A. St Hil \\
\hline ANACARDIACEAE & Lithraea brasiliensis March \\
\hline ANACARDIACEAE & Lithraea molleoides (Vell.) Engl. \\
\hline ANACARDIACEAE & Schinus lentiscifolius Marchand \\
\hline ANACARDIACEAE & Schinus terebinthifolius Raddi \\
\hline ANACARDIACEAE & Schinus weinmannifolius Mart. ex Engler \\
\hline ANACARDIACEAE & Tapirira guianensis Aubl \\
\hline ANEMIACEAE & Anemia anthriscifolia Schrad \\
\hline ANNONACEAE & Annona cacans Warm. \\
\hline ANNONACEAE & Annona coriacea Mart. \\
\hline ANNONACEAE & Annona cornifolia St. Hil. \\
\hline ANNONACEAE & Annona crassiflora Mart \\
\hline ANNONACEAE & Annona dioica A St Hill \\
\hline ANNONACEAE & Duguetia furfuracea A St Hil \\
\hline ANNONACEAE & Duguetia lanceolata A St Hil \\
\hline ANNONACEAE & Guatteria australis A St Hil \\
\hline ANNONACEAE & Rollinia emarginata Schldl \\
\hline ANNONACEAE & Rollinia sylvatica (A St Hil) Mart \\
\hline APIACEAE & Centella asiatica (L.) Blume \\
\hline APIACEAE & Eryngium ebracteatum Lam \\
\hline APIACEAE & Eryngium elegans Cham et Schltdl \\
\hline APIACEAE & Eryngium eriophorum Cham. \& Schltdl. \\
\hline APIACEAE & Eryngium floribundum Cham et Schltdl \\
\hline APIACEAE & Eryngium horridum Malme \\
\hline APIACEAE & Eryngium junceum Cham et Schltdl \\
\hline APIACEAE & Eryngium juncifolium (Urb.) Mathias \& Constance \\
\hline APIACEAE & Eryngium pohlianum Urb \\
\hline APIACEAE & Eryngium pristis Cham. \& Schltdl \\
\hline APIACEAE & Eryngium sanguisorba Cham et Schltdl \\
\hline
\end{tabular}


Anexo 1. Continuação...

\begin{tabular}{|c|c|}
\hline Família & Espécie \\
\hline APIACEAE & Eryngium scirpinum Cham. \& Schltdl. \\
\hline APIACEAE & Eryngium subinerme (Wolff) Math. \& Const \\
\hline APOCYNACEAE & Araujia sericifera Brot. \\
\hline APOCYNACEAE & Aspidosperma camporum Muell. Arg. \\
\hline APOCYNACEAE & Aspidosperma polyneuron Muell.Arg. \\
\hline APOCYNACEAE & Aspidosperma pyrifolium Mart. \\
\hline APOCYNACEAE & Aspidosperma subincanum Mart \\
\hline APOCYNACEAE & Aspidosperma tomentosum Mart. \\
\hline APOCYNACEAE & Barjonia erecta (Vell.) K. Schum. \\
\hline APOCYNACEAE & Blepharodon ampliflorum E. Fourn \\
\hline APOCYNACEAE & Blepharodon bicuspidatum E. Fourn \\
\hline APOCYNACEAE & Blepharodon lineare (Decne.) \\
\hline APOCYNACEAE & Blepharodon nitidum (Vell.) J.F.Macbr. \\
\hline APOCYNACEAE & Condylocarpon isthmicum (Vell.) A. DC. \\
\hline APOCYNACEAE & Ditassa acerosa Mart. \\
\hline APOCYNACEAE & Ditassa edmundoi Fontella \& C. Valente \\
\hline APOCYNACEAE & Ditassa tomentosa (Decne.) Fontella \\
\hline APOCYNACEAE & Forsteronia glabrescens Müll. Arg \\
\hline APOCYNACEAE & Gonioanthela axillaris (Vell.) Fontella \& Schwarz \\
\hline APOCYNACEAE & Hemipogon setaceus Decne \\
\hline APOCYNACEAE & Jobinia lindbergii Fourn. \\
\hline APOCYNACEAE & Macrosiphonia longiflora (Desf.) Müll. Arg. \\
\hline APOCYNACEAE & Macrosiphonia petrae (St. Hil.) K. Schum. \\
\hline APOCYNACEAE & Macrosiphonia virescens (A St Hil) Marg Mull \\
\hline APOCYNACEAE & Mandevilla atroviolacea (Stadelm.) Woodson \\
\hline APOCYNACEAE & Mandevilla coccinea (Hook. \& Arn.) Woodson \\
\hline APOCYNACEAE & Mandevilla erecta (Vell) Woodson \\
\hline APOCYNACEAE & Mandevilla illustris (Vell.) Woodson \\
\hline APOCYNACEAE & Mandevilla pohliana (Stadelm.) A.H. Gentry \\
\hline APOCYNACEAE & Mandevilla velutina (Mart ex Stand) Wood \\
\hline APOCYNACEAE & Nautonia nummularia Decne \\
\hline APOCYNACEAE & Orthosia urceolata Fourn. \\
\hline APOCYNACEAE & Oxypetalum aequaliflorum E. Fourn \\
\hline APOCYNACEAE & Oxypetalum apendiculatum \\
\hline APOCYNACEAE & Oxypetalum arnottianum $\mathrm{H}$. Buek \\
\hline APOCYNACEAE & Oxypetalum capitatum Mart subsp capitatum \\
\hline APOCYNACEAE & Oxypetalum erectum Mart. \\
\hline APOCYNACEAE & Oxypetalum erectum subsp. campestre Hoehne \\
\hline APOCYNACEAE & Oxypetalum lineare Decne. \\
\hline APOCYNACEAE & Oxypetalum malmei Hoehne \\
\hline APOCYNACEAE & Oxypetalum pachygynum Decne \\
\hline APOCYNACEAE & Oxypetalum sublanatum Malme \\
\hline APOCYNACEAE & Oxypetalum suboppositum Malme \\
\hline APOCYNACEAE & Oxypetalum wightianum Hook et Arn \\
\hline APOCYNACEAE & Peltastes peltatus(Vell.) Woodson \\
\hline APOCYNACEAE & Schistogyne mosenii (Malme) T. Mey. \\
\hline APOCYNACEAE & Tabernaemontana catharinensis DC. \\
\hline APOCYNACEAE & Tassadia subulata (Vell.) Fontella \& E.A. Schwarz \\
\hline APOCYNACEAE & Temnadenia stellaris (Lindl) Miers \\
\hline APOCYNACEAE & Temnadenia magnifica (Vell) Miers \\
\hline APOCYNACEAE & Temnadenia violacea (Vell) Miers \\
\hline AQUIFOLIACEAE & Ilex amara (Vcll) Locs \\
\hline AQUIFOLIACEAE & Ilex brevicuspis Reissek \\
\hline AQUIFOLIACEAE & Ilex brasiliensis (Sprengel) Loes. \\
\hline AQUIFOLIACEAE & Ilex dumosa Reissek \\
\hline AQUIFOLIACEAE & Ilex paraguariensisSt.Hill. \\
\hline AQUIFOLIACEAE & Ilex theezans Mart ex Reiss \\
\hline ARACEAE & Anthurium gaudichaudianum Kunth \\
\hline ARALIACEAE & Dendropanax cuneatus (DC.) Decne. \& Planch. \\
\hline ARALIACEAE & Didymopanax vinosum (Cham \& Chltdl)Marchal \\
\hline
\end{tabular}


Composição florística e aspectos físicos de remanescentes de cerrado

Anexo 1. Continuação...

\begin{tabular}{|c|c|}
\hline Família & Espécie \\
\hline ARALIACEAE & Hydrocotile pusilla Rich. \\
\hline ARALIACEAE & Oreopanax fulvum \\
\hline ARALIACEAE & Schefflera angustissima (Marchal) Frodin \\
\hline ARALIACEAE & Schefflera calva (Cham.) Frodin \& Fiaschi \\
\hline ARALIACEAE & Schefflera morototoni \\
\hline ARALIACEAE & Schefflera vinosa (Cham. \& Schltdl.) Frodin \& Fiaschi \\
\hline ARECACEAE & Allagoptera campestris (Mart) Kuntze \\
\hline ARECACEAE & Butia microspadix Burret \\
\hline ARECACEAE & Butia paraguayensis (B. Rodr.) Bailey \\
\hline ARECACEAE & Syagrus hatschbachii Glassman \\
\hline ARECACEAE & Syagrus romanzoffiana (Cham.) Glassman \\
\hline ASPLENIACEAE & Asplenium gastonis Fée \\
\hline ASPLENIACEAE & Asplenium inaequilaterale Willd \\
\hline ASPLENIACEAE & Asplenium radicans $\mathrm{L}$ \\
\hline ASTERACEAE & Acanthospermum australe (Loef.) Kuntze \\
\hline ASTERACEAE & Acanthospermum hispidum DC. \\
\hline ASTERACEAE & Achyrocline satureioides DC \\
\hline ASTERACEAE & Acmella bellidioides (Smith in Rees) R.K. Jansen \\
\hline ASTERACEAE & Actinoseris polymorpha (Less.) Cabrera \\
\hline ASTERACEAE & Ageratum conyzoides $\mathrm{L}$ \\
\hline ASTERACEAE & Ambrosia polystachya DC \\
\hline ASTERACEAE & Angelphytum arnottii (Baker) H. Rob. \\
\hline ASTERACEAE & Angelphytum aspilioides (Griseb.) H. Rob. \\
\hline ASTERACEAE & Aspilia foliacea Baker. \\
\hline ASTERACEAE & Aspilia montevidensis (Spreng) Kuntze \\
\hline ASTERACEAE & Aspilia reflexa Baker \\
\hline ASTERACEAE & Aspilia setosa Griseb \\
\hline ASTERACEAE & Austroeupatorium inulaefolium ( Kunth ) R.M.King \& H.Rob. \\
\hline ASTERACEAE & Austroeupatorium laetevirens (Hook. \& A.) K. et R. \\
\hline ASTERACEAE & Baccharis aphylla (Vell.) DC. \\
\hline ASTERACEAE & Baccharis articulata (Lam.) Pers \\
\hline ASTERACEAE & Baccharis axillaris DC. \\
\hline ASTERACEAE & Baccharis brevifolia DC. \\
\hline ASTERACEAE & Baccharis calvescens DC \\
\hline ASTERACEAE & Baccharis camporum DC. var. camporum \\
\hline ASTERACEAE & Baccharis coridifolia DC \\
\hline ASTERACEAE & Baccharis dentata (Vell.) G.M. Barroso \\
\hline ASTERACEAE & Baccharis dracunculifolia DC \\
\hline ASTERACEAE & Baccharis elliptica Gardner \\
\hline ASTERACEAE & Baccharis erigeroides DC. \\
\hline ASTERACEAE & Baccharis genistelloides (Lam.) Pers \\
\hline ASTERACEAE & Baccharis gracilis DC \\
\hline ASTERACEAE & Baccharis helichrysoides DC \\
\hline ASTERACEAE & Baccharis illinita DC \\
\hline ASTERACEAE & Baccharis megapotamica Spreng. \\
\hline ASTERACEAE & Baccharis megapotamica var. weirii (Baker) Barroso \\
\hline ASTERACEAE & Baccharis microcephala Baker \\
\hline ASTERACEAE & Baccharis milleflora (Less.) DC. \\
\hline ASTERACEAE & Baccharis myricaefolia DC \\
\hline ASTERACEAE & Baccharis myriocephala DC \\
\hline ASTERACEAE & Baccharis pentodonta Malme \\
\hline ASTERACEAE & Baccharis pentziifolia Sch. Bip. ex Baker \\
\hline ASTERACEAE & Baccharis pseudomyriocephala I.L. Teodoro \\
\hline ASTERACEAE & Baccharis pseudotenuifolia $\mathrm{L}$. \\
\hline ASTERACEAE & Baccharis rufescens Spreng \\
\hline ASTERACEAE & Baccharis semiserrata Baker \\
\hline ASTERACEAE & Baccharis sessiliflora Vahl \\
\hline ASTERACEAE & Baccharis stenocephala Baker \\
\hline ASTERACEAE & Baccharis subdentata DC. \\
\hline ASTERACEAE & Baccharis subspathulata Gardner \\
\hline
\end{tabular}


Anexo 1. Continuação...

\begin{tabular}{|c|c|}
\hline Família & Espécie \\
\hline ASTERACEAE & Baccharis tridentata Vahl \\
\hline ASTERACEAE & Baccharis trimera (Less.) DC \\
\hline ASTERACEAE & Baccharis uncinella DC \\
\hline ASTERACEAE & Barrosoa betoniciiformis (DC.) R King \& H.Rob. (= Eupatorium betanicaeforme) \\
\hline ASTERACEAE & Bidens cuneifolia DC \\
\hline ASTERACEAE & Bidens gardneri Baker \\
\hline ASTERACEAE & Bidens pilosa $\mathrm{L}$. \\
\hline ASTERACEAE & Calea acaulis Baker \\
\hline ASTERACEAE & Calea cuneifolia DC \\
\hline ASTERACEAE & Calea cymosa Less \\
\hline ASTERACEAE & Calea hispida (DC.) Baker \\
\hline ASTERACEAE & Calea longifolia Gardner \\
\hline ASTERACEAE & Calea marginata S.F. Blake \\
\hline ASTERACEAE & Calea monocephala Dusen \\
\hline ASTERACEAE & Calea myrtifolia (DC.) Baker \\
\hline ASTERACEAE & Calea parvifolia $\mathrm{Bak}$ \\
\hline ASTERACEAE & Calea platylepis Sch. Bip. ex Baker \\
\hline ASTERACEAE & Calea uniflora Less. \\
\hline ASTERACEAE & Campovassouria cruciata (Vell. Conc.) R. King \& H. Robinson \\
\hline ASTERACEAE & Campuloclinium hirsutum Gardn \\
\hline ASTERACEAE & Campuloclinium macrocephalum (Less) DC \\
\hline ASTERACEAE & Campuloclinium purpurascens (Sch. Bip. exBaker) R.M. King \& H. Rob. \\
\hline ASTERACEAE & Chaptalia graminifolia Dusen \\
\hline ASTERACEAE & Chaptalia integerrima (Vell.) Burkart \\
\hline ASTERACEAE & Chaptalia magnifica(Vell.) Burkart \\
\hline ASTERACEAE & Chaptalia nutans (L.) Polak. \\
\hline ASTERACEAE & Chaptalia piloselloides (Vahl.) Bak. \\
\hline ASTERACEAE & Chresta sphaerocephala DC \\
\hline ASTERACEAE & Chromolaena ascendens (Sch. Bip. ex Baker) R.M. King \& H. Rob. (= Eupatorium ascendens) \\
\hline ASTERACEAE & Chromolaena hirsuta (Hook. \& Arn.) R.M. King \& H. Rob \\
\hline ASTERACEAE & Chromolaena laevigata (Lam)R. M. King \& H. Rob. (= Eupatorium laevigatum) \\
\hline ASTERACEAE & Chromolaena oxylepis (DC.) R. King \& H. Robinson \\
\hline ASTERACEAE & Chromolaena palmaris (Sch. Bip. ex Baker) R.M. King \& H. Rob. (=Eupatorium palmare) \\
\hline ASTERACEAE & Chromolaena sanctopaulensis (B.L. Rob.) R.M.King \& H. Rob. (= Eupatorium sanctopaulense) \\
\hline ASTERACEAE & Chromolaena squalida (DC.) R. King \& H. Robinson (= Eupatorium squalidum ) \\
\hline ASTERACEAE & Chromolaena stachyophylla (Spreng.) R.M. King \& H. Rob \\
\hline ASTERACEAE & Chromolaena verbenacea (DC.) R.M. King \& H.Rob. \\
\hline ASTERACEAE & Chrysolaena flexuosa (Sims) H Rob \\
\hline ASTERACEAE & Chrysolaena hatschbachii H. Rob. \\
\hline ASTERACEAE & Chrysolaena lithospermifolia (Hieron.) H. Rob. \\
\hline ASTERACEAE & Chrysolaena oligophylla (Vell.) H. Rob. \\
\hline ASTERACEAE & Chrysolaena platensis (Spreng.) H. Rob. \\
\hline ASTERACEAE & Chrysolaena verbascifolia (Less.) H. Rob. \\
\hline ASTERACEAE & Conyza bonariensis (L) Cronquist \\
\hline ASTERACEAE & Conyza primulifolia (Lam.) Cuatrec. \& Lourteig \\
\hline ASTERACEAE & Conyza setosa (Baker) Malme \\
\hline ASTERACEAE & Dasyphyllum flagellare (Casar.) Cabrera \\
\hline ASTERACEAE & Dasyphyllum tomentosum (Spreng.) Cabr. \\
\hline ASTERACEAE & Disynaphia calyculata (Hook. \& Arn.) R.M. King \& H. Rob. \\
\hline ASTERACEAE & Disynaphia filifolia (Hassl.) R.M. King \& H. Rob. \\
\hline ASTERACEAE & Disynaphia littoralis (Cabrera) R.M. King \& H. Rob. \\
\hline ASTERACEAE & Disynaphia multicrenulata (Sch. Bip. ex Baker)R.M. King \& H. Rob. \\
\hline ASTERACEAE & Elephantopus mollis Kunth \\
\hline ASTERACEAE & Emilia sagittatta DC \\
\hline ASTERACEAE & Emilia sonchifolia (L.) DC \\
\hline ASTERACEAE & Erechtites hieracifolius (L.) Rafin. ex DC \\
\hline ASTERACEAE & Erechtites valerianifolius (Link ex Spreng.) DC \\
\hline ASTERACEAE & Eupatorium kleinii Cabr. \\
\hline ASTERACEAE & Eupatorium ivaefolium $\mathrm{L}$ \\
\hline ASTERACEAE & Eupatorium kleinni Cabrera \\
\hline
\end{tabular}


Composição florística e aspectos físicos de remanescentes de cerrado

Anexo 1. Continuação...

\begin{tabular}{|c|c|}
\hline Família & Espécie \\
\hline ASTERACEAE & Eupatorium pauciflorum Kunth \\
\hline ASTERACEAE & Eupatorium tanacetifoliumGillies ex Hook et Arn. \\
\hline ASTERACEAE & Eupatorium vauthierianum DC \\
\hline ASTERACEAE & Facelis retusa (Lam) Sch Bip \\
\hline ASTERACEAE & Gamochaeta purpurea (L) Cabrera \\
\hline ASTERACEAE & Gnaphalium cheiranthifolium Lam. \\
\hline ASTERACEAE & Gnaphalium gaudichaudianum DC. \\
\hline ASTERACEAE & Gnaphalium purpureum L. \\
\hline ASTERACEAE & Gochnatia argyrea (Dusén ex Malme) Cabr. \\
\hline ASTERACEAE & Gochnatia paniculata (Less) Cabrera \\
\hline ASTERACEAE & Gochnatia polymorpha (Less.) Cabrera \\
\hline ASTERACEAE & Gochnatia velutina (Bong.) Cabrera \\
\hline ASTERACEAE & Grazielia dimorpholepis (Baker) R.M. King \&H. Rob \\
\hline ASTERACEAE & Grazielia intermedia (DC)R.M. King \&H. Rob \\
\hline ASTERACEAE & Grazielia magnifica DC \\
\hline ASTERACEAE & Grazielia multifida (DC.) R.M. King \& H. Rob (= Eupatorium multifidum) \\
\hline ASTERACEAE & Grazielia multiflora DC \\
\hline ASTERACEAE & Grazielia serrata (Spr.) R.M. King \& H.et Rob \\
\hline ASTERACEAE & Gyptis pinnatifida Cass. \\
\hline ASTERACEAE & Hatschbachiella polyclada (Dusen ex Malme)R.M. King \& H. Rob. \\
\hline ASTERACEAE & Hatschbachiella tweedieana (Hook \& Am) \\
\hline ASTERACEAE & Hyeracium commersonii Monnier \\
\hline ASTERACEAE & Hyeracium ignatianum Baker \\
\hline ASTERACEAE & Holocheilus illustris (Vell.) Cabrera \\
\hline ASTERACEAE & Hypochaeris gardneri Baker \\
\hline ASTERACEAE & Hypochaeris radicata $\mathrm{L}$ \\
\hline ASTERACEAE & Ichthyothere rufa Gardn \\
\hline ASTERACEAE & Inulopsis scaposa (Rem.) O. Hoffm \\
\hline ASTERACEAE & Isostigma speciosum Less \\
\hline ASTERACEAE & Kanimia oblongifolia (DC.) Baker \\
\hline ASTERACEAE & Kanimia strobilifera Gardner. \\
\hline ASTERACEAE & Lessingianthus arachniolepis (Ekman \& Dusén) H. Rob. \\
\hline ASTERACEAE & Lessingianthus argenteus (Less.) H. Rob. \\
\hline ASTERACEAE & Lessingianthus brevifolius (Less) H Rob \\
\hline ASTERACEAE & Lessingianthus brevipetiolatus (Sch. Bip. exBaker) H. Rob. \\
\hline ASTERACEAE & Lessingianthus exiguus (Cabrera) H. Rob. \\
\hline ASTERACEAE & Lessingianthus glabratus (Lees) H Rob \\
\hline ASTERACEAE & Lessingianthus grandiflorus (Less) H Rob \\
\hline ASTERACEAE & Lessingianthus hypochaeris (DC.) H. Rob. \\
\hline ASTERACEAE & Lessingianthus macrocephalus (Less.) H. Rob. \\
\hline ASTERACEAE & Lessingianthus mollissimus (D. Don ex \& Arn.) H. Rob. \\
\hline ASTERACEAE & Lessingianthus niederleinii (Hieron.) H. Rob. \\
\hline ASTERACEAE & Lessingianthus plantaginodes (Kuntze) H. Rob. \\
\hline ASTERACEAE & Lessingianthus polyphyllus (Sch. Bip. ex Baker) H. Rob. \\
\hline ASTERACEAE & Lessingianthus psilophyllus (DC.) H. Rob. \\
\hline ASTERACEAE & Lessingianthus pumilus (Vell.) H. Rob \\
\hline ASTERACEAE & Lessingianthus rubricaulis (Humb. \& Bonpl.) H. Rob \\
\hline ASTERACEAE & Lessingianthus simplex (Less.) H. Rob. \\
\hline ASTERACEAE & Lucilia acutifolia (Poir.) Cassini \\
\hline ASTERACEAE & Lucilia glomerata Baker \\
\hline ASTERACEAE & Lucilia linearifolia Baker \\
\hline ASTERACEAE & Lucilia lycopodioides (Less) S E Freire \\
\hline ASTERACEAE & Melampodium divaricatum (Rich) DC \\
\hline ASTERACEAE & Mikania cynanchifolia Hook. \& Arn. ex B.Rob \\
\hline ASTERACEAE & Mikania decumbens Malme \\
\hline ASTERACEAE & Mikania fulva (Hook \& Arn.) Baker \\
\hline ASTERACEAE & Mikania micrantha Kunth \\
\hline ASTERACEAE & Mikania microcephala DC \\
\hline ASTERACEAE & Mikania hoffmanniana var. microphylla Malme \\
\hline ASTERACEAE & Mikania hoffmanniana Dusén \\
\hline
\end{tabular}


Anexo 1. Continuação...

\begin{tabular}{|c|c|}
\hline Família & Espécie \\
\hline ASTERACEAE & Mikania oblongifolia DC. \\
\hline ASTERACEAE & Mikania officinallis Mart. \\
\hline ASTERACEAE & Mikania sessilifolia DC. \\
\hline ASTERACEAE & Mikania triphylla Spreng ex Baker \\
\hline ASTERACEAE & Noticastrum calvatum (Baker) Cuatrec \\
\hline ASTERACEAE & Ophryosporus laxiflorus Baker \\
\hline ASTERACEAE & Orthopappus angustifolius (Sw.) Gleason \\
\hline ASTERACEAE & Pamphalea smithii Cabrera \\
\hline ASTERACEAE & Perezia squarrosa Less. \\
\hline ASTERACEAE & Piptocarpha angustifolia Dusen ex Malme \\
\hline ASTERACEAE & Piptocarpha axillaris (Less) Bak. \\
\hline ASTERACEAE & Piptocarpha regnelli (Sch Bip) Cabrera \\
\hline ASTERACEAE & Podocoma rivularis (Gardner) G L Neson \\
\hline ASTERACEAE & Porophyllum obscurum (Spreng.) DC. \\
\hline ASTERACEAE & Porophyllum ruderale (Jacq.) Cass \\
\hline ASTERACEAE & Praxelis grandiflora (DC.) Sch. Bip. \\
\hline ASTERACEAE & Praxelis kleinioides (Kunth) Sch. Bip \\
\hline ASTERACEAE & Praxelis pauciflora (Kunth) R. King \& H. Robinson \\
\hline ASTERACEAE & Praxelis sanctopaulensis (B.L. Robinson) R.M. King \& H. Rob. \\
\hline ASTERACEAE & Pterocaulon alopecuroides (Lam) DC \\
\hline ASTERACEAE & Pterocaulon angustifolium DC \\
\hline ASTERACEAE & Pterocaulon rugosum (Vahl) Malme \\
\hline ASTERACEAE & Raulinoreitzia crenulata (Spreng.) R.M. King \&H. Rob. \\
\hline ASTERACEAE & Richterago polymorpha (Less.) Roque \\
\hline ASTERACEAE & Richterago radiata (Vell.) Roque \\
\hline ASTERACEAE & Schlechtendalia luzulifolia Less. \\
\hline ASTERACEAE & Senecio brasiliensis (Spreng) Less \\
\hline ASTERACEAE & Senecio grisebachii Baker var. leptotus Cabrera \\
\hline ASTERACEAE & Senecio hoehnei Cabrera \\
\hline ASTERACEAE & Senecio icoglossus DC. \\
\hline ASTERACEAE & Senecio leptoschizus Bong. \\
\hline ASTERACEAE & Senecio linearilobus Bong. \\
\hline ASTERACEAE & Senecio oleosus Vell. \\
\hline ASTERACEAE & Senecio paulensis Bong. \\
\hline ASTERACEAE & Senecio pulcher Hook. \& Arn. \\
\hline ASTERACEAE & Senecio vernonioides $\mathrm{Sch}$. Bip. \\
\hline ASTERACEAE & Solidago chilensis Meyen \\
\hline ASTERACEAE & Solidago microglossa DC. \\
\hline ASTERACEAE & Spilanthes grisea (Chodat) A.H. Moore \\
\hline ASTERACEAE & Stenachaenium megapotamicum Baker \\
\hline ASTERACEAE & Stenocephalum hexanthum Sch. Bip. \\
\hline ASTERACEAE & Stenocephalum megapotamicum (Spreng) Sch Bip. \\
\hline ASTERACEAE & Stevia alternifolia Hieron \\
\hline ASTERACEAE & Stevia clausseni Sch Bip ex Baker \\
\hline ASTERACEAE & Stevia collina Gardner \\
\hline ASTERACEAE & Stevia commixta B.L. Rob. \\
\hline ASTERACEAE & Stevia crenulata Baker \\
\hline ASTERACEAE & Stevia gardeniana Baker \\
\hline ASTERACEAE & Stevia leptophylla Sch. Bip ex Baker \\
\hline ASTERACEAE & Stevia linearifolia Walp. \\
\hline ASTERACEAE & Stevia lundiana $\mathrm{DC}$ \\
\hline ASTERACEAE & Stevia ophryophylla B.L. Rob. \\
\hline ASTERACEAE & Stevia satureifolia (Lam.) Cav. \\
\hline ASTERACEAE & Stevia urticifolia Thunb. \\
\hline ASTERACEAE & Stevia veronicae DC. \\
\hline ASTERACEAE & Stomatanthes oblongifolius (Spreng.) H. Rob. \\
\hline ASTERACEAE & Stomatanthes subcapitatus (Malme) G. M. Barroso \\
\hline ASTERACEAE & Symphyopappus compressus (Gardn.) B.L \\
\hline ASTERACEAE & Symphyopappus cuneatus (DC) Sch Bip. Ex Baker \\
\hline ASTERACEAE & Symphyopappus reticulatus Baker \\
\hline
\end{tabular}


Composição florística e aspectos físicos de remanescentes de cerrado

Anexo 1. Continuação...

\begin{tabular}{|c|c|}
\hline Família & Espécie \\
\hline ASTERACEAE & Symphyotrichum squamatum (Spreng.) G.L. \\
\hline ASTERACEAE & Trichocline linearifolia Malme \\
\hline ASTERACEAE & Trichocline speciosa Less. \\
\hline ASTERACEAE & Trichogonia chodatii (Hassl.) R.M. King \& H.Rob. \\
\hline ASTERACEAE & Trixis brasiliensis (L.) DC. \\
\hline ASTERACEAE & Trixis verbascifolia (Gardner) S F Blake \\
\hline ASTERACEAE & Verbesina sordescens DC \\
\hline ASTERACEAE & Vernonanthura crassa (Vell.) H. Rob. \\
\hline ASTERACEAE & Vernonanthuta discolor (Spreng.) Less. \\
\hline ASTERACEAE & Vernonanthura mucronulata (Less.) H. Rob \\
\hline ASTERACEAE & Vernonanthura nudiflora (Less.) H. Rob. \\
\hline ASTERACEAE & Vernonanthura oligactoides (Less.) H. Rob. \\
\hline ASTERACEAE & Vernonanthura oligolepis (Sch. Bip.) H. Rob. \\
\hline ASTERACEAE & Vernonanthura petiolaris (DC.) Kuntze \\
\hline ASTERACEAE & Vernonanthura tweedieana (Baker) H. Rob. \\
\hline ASTERACEAE & Vernonanthura westiniana (Less.) H. Rob. \\
\hline ASTERACEAE & Vernonia cataractarum \\
\hline ASTERACEAE & Vernonia cognata Less. \\
\hline ASTERACEAE & Vernonia flexuosa Sims \\
\hline ASTERACEAE & Vernonia glabrata Less. \\
\hline ASTERACEAE & Vernonia grandiflora Less \\
\hline ASTERACEAE & Vernonia herbacea (Vell.) Rusby \\
\hline ASTERACEAE & Vernonia intermedia $\mathrm{DC}$ \\
\hline ASTERACEAE & Vernonia magnifica Juss \\
\hline ASTERACEAE & Vernonia mollissima D.Don \\
\hline ASTERACEAE & Viguiera aspilioides Baker \\
\hline ASTERACEAE & Viguiera macrorhiza Baker \\
\hline ASTERACEAE & Viguiera trichophylla Dusen \\
\hline ASTERACEAE & Vittetia orbiculata (DC.) R.M. King \& H. Rob. \\
\hline ASTERACEAE & Xanthium spinosum $\mathrm{L}$. \\
\hline BASELLACEAE & Anredera cordifolia (Ten.) Steenis \\
\hline BEGONIACEAE & Begonia cucullata Willd \\
\hline BEGONIACEAE & Begonia fischeri Schrank \\
\hline BEGONIACEAE & Begonia setosa $\mathrm{Kl}$. \\
\hline BIGNONIACEAE & Anemopaegma arvense (Vell.) Stellfeld ex J. F. Souza \\
\hline BIGNONIACEAE & Arrabidaea chica (Humb. \& Bonpl.) Verl \\
\hline BIGNONIACEAE & Arrabidaea pulchella (Cham.) Bureau \\
\hline BIGNONIACEAE & Arrabidaea samydoides (Cham.) Sandwith \\
\hline BIGNONIACEAE & Cybistax antysiphilitica (Mart.) Mart. \\
\hline BIGNONIACEAE & Clytostoma binatum (Thunb.) Sandwith \\
\hline BIGNONIACEAE & Cuspidaria convoluta (Vell.) A.H. Gentry \\
\hline BIGNONIACEAE & Distictella mansoana (DC.) Urban \\
\hline BIGNONIACEAE & Fridericia speciosa Mart \\
\hline BIGNONIACEAE & Jacaranda micrantha Cham \\
\hline BIGNONIACEAE & Jacaranda oxyphylla Cham \\
\hline BIGNONIACEAE & Jacaranda puberula Cham \\
\hline BIGNONIACEAE & Pyrostegia venusta (Ker Gawl) Miers \\
\hline BIGNONIACEAE & Tabebuia alba (Cham) Sandwith \\
\hline BIGNONIACEAE & Tabebuia aurea (Manso) Benth \& Hooker \\
\hline BIGNONIACEAE & Tabebuia chrysotricha Mart ex A. DC \\
\hline BIGNONIACEAE & Tabebuia ochraceae (Cham) Standl. \\
\hline BIGNONIACEAE & Tabebuia pulcherrima Sandwitch \\
\hline BIGNONIACEAE & Zeyheria montana Mart \\
\hline BLECHNACEAE & Blechnum brasiliense Desv. \\
\hline BLECHNACEAE & Blechnum cordatum (Desv.)Hieron. \\
\hline BLECHNACEAE & Blechnum divergens(Kunze) Mett \\
\hline BLECHNACEAE & Blechnum laevigatum $\mathrm{Cav}$ \\
\hline BLECHNACEAE & Blechnum polypodioides Raddi \\
\hline BLECHNACEAE & Blechnum schomburgki (Klotzsch) C. Chr. \\
\hline BORAGINACEAE & Cordia rufescens A. DC. \\
\hline
\end{tabular}


Anexo 1. Continuação...

\begin{tabular}{|c|c|}
\hline Família & Espécie \\
\hline BORAGINACEAE & Moritzia ciliata (Cham.) DC. ex Meisn. \\
\hline BORAGINACEAE & Moritzia dasyantha (Cham.) Fresen. \\
\hline BORAGINACEAE & Moritzia dusenii I M Johnst \\
\hline BORAGINACEAE & Moritzia tetraquetra (Cham.) Brand. \\
\hline BROMELIACEAE & Acanthostachys strobilacea (Schult. \& Schult.f.) Klotzch \\
\hline BROMELIACEAE & Aechmea bromeliifolia (Rudge) Baker \\
\hline BROMELIACEAE & Aechmea recurvata (Klotzsch) LB Sim \\
\hline BROMELIACEAE & Aechmea recurvata var. ortgiesii (Baker) Reitz \\
\hline BROMELIACEAE & Bilbergia distachia (Vell.) Mez \\
\hline BROMELIACEAE & Dyckia brevifolia Baker \\
\hline BROMELIACEAE & Dyckia crocea L.B.Smith \\
\hline BROMELIACEAE & Dyckia fosteriana L.B.Smith \\
\hline BROMELIACEAE & Dyckia leptostachya Baker \\
\hline BROMELIACEAE & Dyckia lutziana L.B.Smith \\
\hline BROMELIACEAE & Dyckia pseudococcinea L.B.Smith \\
\hline BROMELIACEAE & Dickia tuberosa (Vell) Beer \\
\hline BROMELIACEAE & Platyaechmea distichantha (Lem.) L.B.Smith \& W.J.Kress \\
\hline BROMELIACEAE & Pitcairnia flammea Lindl \\
\hline BROMELIACEAE & Tillandsia crocata (Morren) Baker \\
\hline BROMELIACEAE & Tillandsia gardneri Lindl \\
\hline BROMELIACEAE & Tillandsia geminiflora Brongn \\
\hline BROMELIACEAE & Tillandsia lorentziana Griseb. \\
\hline BROMELIACEAE & Tillandsia mallemontii Glaziou ex Mez \\
\hline BROMELIACEAE & Tillandsia meridionalis Baker \\
\hline BROMELIACEAE & Tillandsia recurvata (L.) L. \\
\hline BROMELIACEAE & Tillandsia streptocarpa Baker \\
\hline BROMELIACEAE & Tillandsia stricta Soland \\
\hline BROMELIACEAE & Tillandsia tenuifolia $\mathrm{L}$. \\
\hline BROMELIACEAE & Tillandsia tenuifolia var. surinamensis (Mez)L.B. Sm. \\
\hline BROMELIACEAE & Tillandsia usneoides (L.) L. \\
\hline BROMELIACEAE & Vriesea ensiformis (Vell.) Beer \\
\hline BROMELIACEAE & Vriesea friburgensis $\mathrm{Mez}$ \\
\hline BROMELIACEAE & Vriesea platynema Gaudich. \\
\hline CACTACEAE & Cereus hildmannianus K.Schum. \\
\hline CACTACEAE & Cereus jamacaru DC. \\
\hline CACTACEAE & Cereus peruvianus L. J.S. Muell \\
\hline CACTACEAE & Hatiora salicornioides (Haw) Britton \& Rose \\
\hline CACTACEAE & Lepismium cruciforme (Vell.) Miq. \\
\hline CACTACEAE & Lepismium houlletianum (Lem) Barthlott \\
\hline CACTACEAE & Lepismium lumbricoides (Lemaire) Barthlott \\
\hline CACTACEAE & Parodia ottonis var. villa-velhensis (Brack. \& Voll) N. P. Taylor \\
\hline CACTACEAE & Rhipsalis baccifera Stearn \\
\hline CACTACEAE & Rhipsalis cereuscula Haw. \\
\hline CACTACEAE & Rhipsalis dissimilis (G Lindb) K Shum \\
\hline CACTACEAE & Rhipsalis neves-armondii $\mathrm{K}$. Schum. \\
\hline CALOPHYLLACEAE & Calophyllum brasiliense Cambess. \\
\hline CALOPHYLLACEAE & Kielmeyera coriacea Mart \\
\hline CALOPHYLLACEAE & Kielmeyera paranaensis Saddi \\
\hline CALOPHYLLACEAE & Kielmeyera variabilis Mart \\
\hline CAMPANULACEAE & Lobelia camporum Pohl \\
\hline CAMPANULACEAE & Lobelia exaltata Pohl \\
\hline CAMPANULACEAE & Lobelia nummularioides Cham. \\
\hline CAMPANULACEAE & Pratia hederacea (Cham.) G. Don. \\
\hline CAMPANULACEAE & Siphocampylus lycioides (Cham.) G. Don. \\
\hline CAMPANULACEAE & Siphocampylus macropodus (Billb.) G. Don \\
\hline CAMPANULACEAE & Siphocampylus sulfureus E. Wimmer \\
\hline CAMPANULACEAE & Siphocampylus verticilatus (Cham.) G Don \\
\hline CAMPANULACEAE & Wahlenbergia linarioides (Lam) A DC \\
\hline CANNABACEAE & Trema micrantha (L.) Blume \\
\hline CANELLACEAE & Capsicodendron dinisii (Schwacke) Occhioni \\
\hline
\end{tabular}


Composição florística e aspectos físicos de remanescentes de cerrado

Anexo 1. Continuação...

\begin{tabular}{|c|c|}
\hline Família & Espécie \\
\hline CARDIOPTERIDACEAE & Citronella paniculata (Mart.) R.A. Howard \\
\hline CARYOCARACEAE & Caryocar brasiliense Cambess. \\
\hline CARYOPHYLLACEAE & Arenaria lanuginosa (Michx.) Rohrb. \\
\hline CARYOPHYLLACEAE & Cerastium commersonianum DC. \\
\hline CARYOPHYLLACEAE & Cerastium dicrotrichum Fenzl ex Rohrbach \\
\hline CARYOPHYLLACEAE & Cerastium selloi Schltdl. ex Rohrb. \\
\hline CARYOPHYLLACEAE & Paronychia chilensis DC. \\
\hline CARYOPHYLLACEAE & Polycarpaea corymbosa (L.) Lam \\
\hline CARYOPHYLLACEAE & Stellaria media (L.) Vill. \\
\hline CELASTRACEAE & Maytenus evonymoides (Reissek) Lundel \\
\hline CELASTRACEAE & Maytenus robusta Reiss. \\
\hline CELASTRACEAE & Plenckia populnea (Reissek) Lundell \\
\hline CELASTRACEAE & Peritassa campestris (Cambess.) A. C. Sm \\
\hline CELASTRACEAE & Peritassa hatschbachii Lomb. \\
\hline CELASTRACEAE & Pristimera andina Miers \\
\hline CHLORANTHACEAE & Hedyosmum brasiliense Mart. \\
\hline CHRYSOBALANACEAE & Couepia grandiflora (Mart \& Zucc) Benth ex Hook f. \\
\hline CISTACEAE & Halimium brasiliense (Lam.) Pers. \\
\hline CLETHRACEAE & Clethra scabra Pers \\
\hline CLETHRACEAE & Clethra scabra var. venosa (Pers.) Sleum. \\
\hline CLUSIACEAE & Clusia criuva Cambess. \\
\hline CLUSIACEAE & Clusia parviflora Humb \& Bompl ex Wild \\
\hline COMBRETACEAE & Combretum fruticosum (Loefl.) Stuntz \\
\hline COMBRETACEAE & Terminalia argentea Mart. \\
\hline COMMELINACEAE & Commelina benghalensis $\mathrm{L}$. \\
\hline COMMELINACEAE & Commelina difusa Burm $\mathrm{f}$. \\
\hline COMMELINACEAE & Commelina elegans Kunth \\
\hline COMMELINACEAE & Commelina erecta $\mathrm{L}$ \\
\hline COMMELINACEAE & Commelina robusta Kunth \\
\hline COMMELINACEAE & Dichorisandra hexandra(Aubl.) Standl. \\
\hline COMMELINACEAE & Floscopa glabrata (Kunth.) Hassk. \\
\hline COMMELINACEAE & Tradescantia cerinthoides Kunth \\
\hline COMMELINACEAE & Tradescantia blossfeldiana Mildbr. \\
\hline CONVOLVULACEAE & Convolvulus crenatifolius Ruiz \& Pav \\
\hline CONVOLVULACEAE & Convolvulus hasslerianus (Chodat) O`Donell \\
\hline CONVOLVULACEAE & Convolvulus mollis Meisn. \\
\hline CONVOLVULACEAE & Cuscuta racemosa Mart \\
\hline CONVOLVULACEAE & Dichondra microcalyx (Hallier f.) Fabris \\
\hline CONVOLVULACEAE & Dichondra repens J.R. Forst. \& G. Forst. \\
\hline CONVOLVULACEAE & Evolvulus aurigenius Mart. \\
\hline CONVOLVULACEAE & Evolvulus barbatus Meisn \\
\hline CONVOLVULACEAE & Evolvulus latifolius Ker-Gawl. \\
\hline CONVOLVULACEAE & Evolvulus pusillus Choisy \\
\hline CONVOLVULACEAE & Evolvulus sericeus $\mathrm{Sw}$ \\
\hline CONVOLVULACEAE & Ipomoea angustifolia Jacq. \\
\hline CONVOLVULACEAE & Ipomoea argentea Meisn. \\
\hline CONVOLVULACEAE & Ipomoea bonariensis Hook. \\
\hline CONVOLVULACEAE & Ipomoea cairica (L.) Sweet \\
\hline CONVOLVULACEAE & Ipomoea campestris Meisn. \\
\hline CONVOLVULACEAE & Ipomoea coccinea $\mathrm{L}$. \\
\hline CONVOLVULACEAE & Ipomoea delphinioides Choisy \\
\hline CONVOLVULACEAE & Ipomoea grandifolia (Dammer) O’Donell \\
\hline CONVOLVULACEAE & Ipomoea polymorpha Roem. \& Schult. \\
\hline CONVOLVULACEAE & Ipomoea procumbens Mart. \& Choisy \\
\hline CONVOLVULACEAE & Ipomoea procurrens Meisn \\
\hline CONVOLVULACEAE & Ipomoea purpurea (L.) Roth \\
\hline CONVOLVULACEAE & Jacquemontia mucronifera (Choisy) Hallier f. \\
\hline CONVOLVULACEAE & Jacquemontia selloi (Meissner) Hallier \\
\hline CONVOLVULACEAE & Jacquemontia velutina Choisy \\
\hline CONVOLVULACEAE & Merremia digitata (Spreng) Hallier f. \\
\hline
\end{tabular}


Anexo 1. Continuação...

\begin{tabular}{|c|c|}
\hline Família & Espécie \\
\hline CONVOLVULACEAE & Merremia macrocalyx (Ruiz \& Pav.) O’Donell \\
\hline CONVOLVULACEAE & Merremia tomentosa (Choisy) Hall. f. \\
\hline CUCURBITACEAE & Cayaponia espelina (Silva Manso) Cogn. \\
\hline CUCURBITACEAE & Ceratosanthes multiloba Cogn. \\
\hline CUCURBITACEAE & Melancium campestre Naud \\
\hline CYPERACEAE & Bulbostylis brevifolia Palla \\
\hline CYPERACEAE & Bulbostylis capillaris (L.) Kunth \\
\hline CYPERACEAE & Bulbostylis capillaris var. elatior (Griseb.) Osten \\
\hline CYPERACEAE & Bulbostylis filamentosa (Vahl.) C.B.Clark \\
\hline CYPERACEAE & Bulbostylis hirtella Nees \\
\hline CYPERACEAE & Bulbostylis jacobinae (Steud) Lindm \\
\hline CYPERACEAE & Bulbostylis junciformis (Kunth) C.B. Clarke \\
\hline CYPERACEAE & Bulbostylis juncoides var. lorentzii (Boeck.) Kük. \\
\hline CYPERACEAE & Bulbostylis loefgreni A. Prata \& M.G. López \\
\hline CYPERACEAE & Bulbostylis paradoxa (Sreng.) Lindm. \\
\hline CYPERACEAE & Bulbostylis scabra (J. Presl \& C. Presl) C.B.Clarke \\
\hline CYPERACEAE & Bulbostylis sellowiana (Kunth) Palla \\
\hline CYPERACEAE & Bulbostylis sphaerocephala (Boeck.) C.B. Clarke \\
\hline CYPERACEAE & Carex albolutescens Schwein. \\
\hline CYPERACEAE & Carex albolutescens Schwein var. meridionalis \\
\hline CYPERACEAE & Cyperus aggregatus (Willd.) Endl. \\
\hline CYPERACEAE & Carex brasiliensis A. St.-Hil. \\
\hline CYPERACEAE & Cyperus brevifolius Rotth. Hassk \\
\hline CYPERACEAE & Cyperus cayennensis (Lam.) Britton \\
\hline CYPERACEAE & Cyperus densicaespitosus Mattf. \& Kük \\
\hline CYPERACEAE & Cyperus ferax Rich \\
\hline CYPERACEAE & Cyperus haspan $\mathrm{L}$ \\
\hline CYPERACEAE & Cyperus impolitus Kunth \\
\hline CYPERACEAE & Cyperus megapotamicus Kunth \\
\hline CYPERACEAE & Cyperus odoratus L. \\
\hline CYPERACEAE & Cyperus reflexus var. fraternus (Kunth) Kuntze \\
\hline CYPERACEAE & Cyperus rigens J. Presl \& C. Presl var. rigens \\
\hline CYPERACEAE & Cyperus rotundus $\mathrm{L}$. \\
\hline CYPERACEAE & Eleocharis capillacea Kunth \\
\hline CYPERACEAE & Eleocharis filiculmins Kunth \\
\hline CYPERACEAE & Eleocharis nudipes (Kunth) Palla \\
\hline CYPERACEAE & Eleocharis subarticulata (Nees) Boeck. \\
\hline CYPERACEAE & Fimbristylis complanata (Retz) Link \\
\hline CYPERACEAE & Fimbristylis dichotoma (L.) Vahl \\
\hline CYPERACEAE & Fimbristylis diphylla \\
\hline CYPERACEAE & Kyllinga odorata Vahl \\
\hline CYPERACEAE & Lagenocarpus polyphyllus (Nees) Kuntze \\
\hline CYPERACEAE & Lagenocarpus rigidus (Kunth) Nees \\
\hline CYPERACEAE & Lipocarpha humboldtiana Nees \\
\hline CYPERACEAE & Rhynchospora albiceps Kunth \\
\hline CYPERACEAE & Rhynchospora brasiliensis Boeck \\
\hline CYPERACEAE & Rhynchospora confinis (Nees) C B Clarke \\
\hline CYPERACEAE & Rhynchospora consanguinea (Kunth) Boeck \\
\hline CYPERACEAE & Rhynchospora corymbosa $(\mathrm{L})$ Britan \\
\hline CYPERACEAE & Rhynchospora corymbosa var. asperula (Nees)Kunth \\
\hline CYPERACEAE & Rhynchospora emaciata (Nees) Boeck. \\
\hline CYPERACEAE & Rhynchospora exaltata Kunth \\
\hline CYPERACEAE & Rhynchospora globosa Roem. Et Schult \\
\hline CYPERACEAE & Rhynchospora gollmeri Boeck. \\
\hline CYPERACEAE & Rhynchospora loefgrenii Boeck \\
\hline CYPERACEAE & Rhynchospora marisculus Lindl. ex Nees \\
\hline CYPERACEAE & Rhynchospora paranaensis A.C. Araujo \&.W. Thomas \\
\hline CYPERACEAE & Rhynchospora rigida (Kunth) Boeck. \\
\hline CYPERACEAE & Rhynchospora robusta(Kunth) Boeck. \\
\hline CYPERACEAE & Rhynchospora rugosa (Vahl) S. Galé \\
\hline
\end{tabular}


Anexo 1. Continuação...

\begin{tabular}{|c|c|}
\hline Família & Espécie \\
\hline CYPERACEAE & Rhynchospora setigera (Kunth) Boeck \\
\hline CYPERACEAE & Rhynchospora tenella (Nees) Boeck \\
\hline CYPERACEAE & Rhynchospora tenuis Link \\
\hline CYPERACEAE & Rhynchospora velutina (Kunth) Boeck. \\
\hline CYPERACEAE & Scleria hirtella $\mathrm{Sw}$ \\
\hline CYPERACEAE & Scleria latifolia $\mathrm{Sw}$ \\
\hline CYPERACEAE & Scleria leptostachya Kunth \\
\hline DENNSTAEDTIACEAE & Pteridium arachnoideum (Kaufl) Maxon \\
\hline DROSERACEAE & Drosera brevifolia Pursh \\
\hline DROSERACEAE & Drosera communis A. St.-Hil \\
\hline DROSERACEAE & Drosera villosa A. St.-Hil. \\
\hline EBENACEAE & Diospyros hispida A DC \\
\hline ERICACEAE & Agarista pulchella (Cham) ex G Don(=Leucothoe) \\
\hline ERICACEAE & Gaylussacia brasiliensis (Spreng.) Meisn. \\
\hline ERICACEAE & Gaylussacia brasiliensis var. nervosa Meisn. \\
\hline ERICACEAE & Gaylussacia brasiliensis var. pubescens (Cham.\& Schltdl.) Meisn. \\
\hline ERICACEAE & Gaylussacia pseudogaultheria Cham \& Schltdl \\
\hline ERIOCAULACEAE & Actinocephalus polyanthus (Bong.) Sano \\
\hline ERIOCAULACEAE & Eriocaulon kunthii Körn. \\
\hline ERIOCAULACEAE & Eriocaulon ligulatum (Vell.) L.B. Sm. \\
\hline ERIOCAULACEAE & Eriocaulon sellowianum Kunth \\
\hline ERIOCAULACEAE & Eriocaulon vaginatum Koern. \\
\hline ERIOCAULACEAE & Leiothrix flavescens (Bong.) Ruhland \\
\hline ERIOCAULACEAE & Paepalanthus albo-vaginatus Alv. Silv \\
\hline ERIOCAULACEAE & Paepalanthus catharinae Ruhland \\
\hline ERIOCAULACEAE & Paepalanthus caldensis Silveira \\
\hline ERIOCAULACEAE & Paepalanthus corymboides var. epilosus Ruhl. \\
\hline ERIOCAULACEAE & Paepalanthus hydra Ruhland \\
\hline ERIOCAULACEAE & Paepalanthus leucocephala \\
\hline ERIOCAULACEAE & Paepalanthus paulensis Ruhland \\
\hline ERIOCAULACEAE & Paepalanthus planifolius (Bong.) Körn. \\
\hline ERIOCAULACEAE & Paepalanthus polyanthus (Bong.) Kunth \\
\hline ERIOCAULACEAE & Paepalanthus ruhlandii Alv. Silv. \\
\hline ERIOCAULACEAE & Syngonanthus caulescens (Poir.) Ruhl \\
\hline ERIOCAULACEAE & Syngonanthus gracilis (Bong.) Ruhland \\
\hline ERIOCAULACEAE & Syngonanthus nitens (Bong.) Ruhl. \\
\hline ERYTHROXYLACEAE & Erythroxylum buxus Peyr \\
\hline ERYTHROXYLACEAE & Erythroxylum campestre St. Hil. \\
\hline ERYTHROXYLACEAE & Erythroxylum cuneifolium (Mart)O E Schulz \\
\hline ERYTHROXYLACEAE & Erythroxylum deciduum A St Hil \\
\hline ERYTHROXYLACEAE & Erythroxylum microphyllum A. St.-Hil. \\
\hline ERYTHROXYLACEAE & Erythroxylum nanum A. St.-Hil. \\
\hline ERYTHROXYLACEAE & Erythroxylum suberosum St Hill \\
\hline ESCALLONIACEAE & Escallonia farinacea A. St.Hil. \\
\hline EUPHORBIACEAE & Alchornea irucurana Casar. \\
\hline EUPHORBIACEAE & Alchornea triplinervia (Spreng) Muell. Arg. \\
\hline EUPHORBIACEAE & Chamaesyce caecorum (Mart. ex Boiss.) Croizat \\
\hline EUPHORBIACEAE & Chamaesyce potentilloides (Boiss.) Croizat \\
\hline EUPHORBIACEAE & Croton antissiphyliticus Muell Arg \\
\hline EUPHORBIACEAE & Croton ceanothifolius Baill. \\
\hline EUPHORBIACEAE & Croton ericoides Baill. \\
\hline EUPHORBIACEAE & Croton floribundus Spreng. \\
\hline EUPHORBIACEAE & Croton glandulosus L. \\
\hline EUPHORBIACEAE & Croton glechomifolius Muell. Arg. \\
\hline EUPHORBIACEAE & Croton grandivelum Baill. \\
\hline EUPHORBIACEAE & Croton heterodoxus Baill. \\
\hline EUPHORBIACEAE & Croton leptophyllus Müll. Arg. \\
\hline EUPHORBIACEAE & Croton lundianus Müll. Arg \\
\hline EUPHORBIACEAE & Croton migrans Casar. \\
\hline EUPHORBIACEAE & Croton pallidulus var. myrianthus (Muell. Arg.) \\
\hline
\end{tabular}


Anexo 1. Continuação...

\begin{tabular}{|c|c|}
\hline Família & Espécie \\
\hline EUPHORBIACEAE & Croton pycnocephalus Muel. Arg \\
\hline EUPHORBIACEAE & Croton pohlianus Müll. Arg \\
\hline EUPHORBIACEAE & Croton serpyllifolius Baill. \\
\hline EUPHORBIACEAE & Dalechampia glechomifolia Baill. \\
\hline EUPHORBIACEAE & Dalechampia micromeria Baill. \\
\hline EUPHORBIACEAE & Dalechampia trichophila Pax \& K. Hoffm \\
\hline EUPHORBIACEAE & Euphorbia heterophylla L. \\
\hline EUPHORBIACEAE & Euphorbia hirta var. ophtalmica (Pers.) Allem\& Irgang \\
\hline EUPHORBIACEAE & Euphorbia peperomioides Boiss. \\
\hline EUPHORBIACEAE & Hieronyma alchorneoides \\
\hline EUPHORBIACEAE & Julocroton humilis Mull Arg \\
\hline EUPHORBIACEAE & Julocroton solanaceus Muell. Arg \\
\hline EUPHORBIACEAE & Pera glabrata (Schott) Baill. \\
\hline EUPHORBIACEAE & Pera obovata Baill \\
\hline EUPHORBIACEAE & Sapium grandulatum (Vell) Pax \\
\hline EUPHORBIACEAE & Sebastiana brasiliensis Spreng. \\
\hline EUPHORBIACEAE & Sebastiania hispida (Mart.) Pax \\
\hline EUPHORBIACEAE & Tragia bahiensis Müll. Arg. \\
\hline EUPHORBIACEAE & Tragia sellowiana (Baill.) Müll. Arg. \\
\hline EUPHORBIACEAE & Tragia volubilis $\mathrm{L}$. \\
\hline FABACEAE & Acacia polyphylla DC. \\
\hline FABACEAE & Acosmium subelegans (Mohlenbr) Yakovlev \\
\hline FABACEAE & Aeschynomene falcata (Poir) DC \\
\hline FABACEAE & Aeschynomene histrix Poir. \\
\hline FABACEAE & Anadenanthera collubrina (Vell.) Brenan \\
\hline FABACEAE & Anadenanthera falcata (Benth.) Speg. \\
\hline FABACEAE & Anadenanthera peregrina (L.) Speg. \\
\hline FABACEAE & Andira fraxinifolia Benth. \\
\hline FABACEAE & Andira humilis Mart ex Benth \\
\hline FABACEAE & Andira laurifolia Benth. \\
\hline FABACEAE & Bauhinia forficata Link. \\
\hline FABACEAE & Bauhinia holophylla (Bong) Steud \\
\hline FABACEAE & Bauhinia rufa (Bong) Steud \\
\hline FABACEAE & Bowdichia virgiloides Kunth in $\mathrm{HBK}$ \\
\hline FABACEAE & Caesalpinia rubicunda (Vog.) Benth. \\
\hline FABACEAE & Caesalpinia stipularis (Vog) Benth \\
\hline FABACEAE & Calliandra brevipes Benth. \\
\hline FABACEAE & Calliandra dysantha Benth. Var. macrocephala (Benth.) \\
\hline FABACEAE & Calliandra selloi (Spr.) McBr. \\
\hline FABACEAE & Calopogonium sericeum (Benth.) Chod. \& Hassl. \\
\hline FABACEAE & Camptosema scarlatinum (Mart. Ex Benth.) Burkart \\
\hline FABACEAE & Cassia desvauxii Collad. \\
\hline FABACEAE & Cassia rotundifolia Pers \\
\hline FABACEAE & Centrolobium tomentosum Guill. ex Benth. \\
\hline FABACEAE & Centrosema angustifolium (Kunth) Benth \\
\hline FABACEAE & Centrosema bracteosum Benth \\
\hline FABACEAE & Centrosema brasilianum (L.) Benth. \\
\hline FABACEAE & Centrosema pubescens Benth \\
\hline FABACEAE & Centrosema virginianum (L.) Benth. \\
\hline FABACEAE & Chamaecrista cardiostegia H S Irwin \& Barn \\
\hline FABACEAE & Chamaecrista cathartica (Mart) H S Irwin \& Barn. \\
\hline FABACEAE & Chamaecrista desvauxii (Collad) Killipvar \\
\hline FABACEAE & Chamaecrista desvauxii (Collad.) Killip var. triumviralis \\
\hline FABACEAE & Chamaecrista desvauxii (Collad.) Killipvar var langsdorffii \\
\hline FABACEAE & Chamaecrista desvauxii var. molissima (Benth.) H. S. Irwin \& Barneby \\
\hline FABACEAE & Chamaecrista incana (Vogel) H.S.Irwin \& Barneby \\
\hline FABACEAE & Chamaecrista nictitans (L.) Moench \\
\hline FABACEAE & Chamaecrista nictitans subsp. brachypoda(Benth.) H.S. Irwin \\
\hline FABACEAE & Chamaecrista nictitans subsp. patellaria (DCex Collad.) H.S. Irwin \& Barneby var. patellaria \\
\hline FABACEAE & Chamaecrista punctata (Vogel) H.S.Irwin \& Barn. \\
\hline
\end{tabular}


Composição florística e aspectos físicos de remanescentes de cerrado

Anexo 1. Continuação...

\begin{tabular}{|c|c|}
\hline Família & Espécie \\
\hline FABACEAE & Chamaecrista ramosa (Vog.) H.S.Irwin \& Barn. var. erythrocalyx \\
\hline FABACEAE & Chamaecrista ramosa (Vogel) H.S. Irwin \& Barneby \\
\hline FABACEAE & Chamaecrista ramosa (Vogel) H.S.Irwin \& Barn. var. parvifolia \\
\hline FABACEAE & Chamaecrista repens (Vogel) H.S. Irwin \&Barneby var. repens \\
\hline FABACEAE & Chamaecrista rotundifolia (Pers.) Greene \\
\hline FABACEAE & Chamaecrista serpens (L.) Greene var. serpens \\
\hline FABACEAE & Chamaecrista vestita (Vogel) H.S. Irwin \& Barn. \\
\hline FABACEAE & Clitoria epetiolata Burkart \\
\hline FABACEAE & Clitoria falcata Lam. \\
\hline FABACEAE & Clitoria guianensis (Aubl) Benth \\
\hline FABACEAE & Clitoria rubiginosa Adr. Juss. ex Pers. \\
\hline FABACEAE & Clitoria rufescens Benth \\
\hline FABACEAE & Collaea aschersoniana (Taub.) Burkart \\
\hline FABACEAE & Collaea speciosa DC \\
\hline FABACEAE & Collaea stenophylla (Hook. \& Arn.) Benth. \\
\hline FABACEAE & Copaifera langsdorffii Desf \\
\hline FABACEAE & Copaifera trapezifolia Hayne \\
\hline FABACEAE & Crotalaria balansae Micheli \\
\hline FABACEAE & Crotalaria hilariana Benth. \\
\hline FABACEAE & Crotalaria maypurensis Kunth \\
\hline FABACEAE & Crotalaria micans Link \\
\hline FABACEAE & Crotalaria velutina Benth \\
\hline FABACEAE & Dalbergia brasiliensis Vogel \\
\hline FABACEAE & Dalbergia miscolobium Benth \\
\hline FABACEAE & Desmanthus tatuhyensis Hoehne \\
\hline FABACEAE & Desmodium adscendens (Sw.) DC. \\
\hline FABACEAE & Desmodium arechavaletae Burkart \\
\hline FABACEAE & Desmodium barbatum (L.) Benth \\
\hline FABACEAE & Desmodium canum (J.F. Gmel.) Schinz \& Thell. \\
\hline FABACEAE & Desmodium craspediferum A. M. G. deAzevedo \& M. de L.A.A. de Oliveira \\
\hline FABACEAE & Desmodium cuneatum Hook. \& Arn. \\
\hline FABACEAE & Desmodium discolor Vogel \\
\hline FABACEAE & Desmodium dutrae Malme \\
\hline FABACEAE & Desmodium incanum DC \\
\hline FABACEAE & Desmodium leiocarpum (Spreng) G Don \\
\hline FABACEAE & Desmodium pachyrrhizum Vogel \\
\hline FABACEAE & Desmodium polygaloides Chodat \& Hassl. \\
\hline FABACEAE & Desmodium tortuosum (SW) DC \\
\hline FABACEAE & Desmodium uncinatum (Jacq.) DC. \\
\hline FABACEAE & Eriosema campestre Benth \\
\hline FABACEAE & Eriosema crinitium var macrophyllum Grear \\
\hline FABACEAE & Eriosema crinitum (Kunth) G. Don var.crinitum \\
\hline FABACEAE & Eriosema crinitum var. fusiformis (Rusby)Grear \\
\hline FABACEAE & Eriosema glabrum Mart. ex Benth. \\
\hline FABACEAE & Eriosema heterophylum Benth \\
\hline FABACEAE & Eriosema longifolium Benth. \\
\hline FABACEAE & Eriosema longifolium var pedunculatum Chodat \& Hassl \\
\hline FABACEAE & Eriosema obovatum Benth \\
\hline FABACEAE & Eriosema obovatum Benth. \\
\hline FABACEAE & Galactia benthamiana Micheli \\
\hline FABACEAE & Galactia boavista (Vell) Burkart \\
\hline FABACEAE & Galactia decumbens (Benth.) Hoehne \\
\hline FABACEAE & Galactia macrophylla (Benth) Taub \\
\hline FABACEAE & Galactia martii DC. \\
\hline FABACEAE & Galactia martii var. acuta Burkart \\
\hline FABACEAE & Galactia neesii DC \\
\hline FABACEAE & Galactia pretiosa Burk. \\
\hline FABACEAE & Indigofera asperifolia Bong. ex Benth. \\
\hline FABACEAE & Indigofera bongardiana (Kuntze) Burkart \\
\hline FABACEAE & Indigofera campestris Bong. \\
\hline
\end{tabular}


Ritter, L.M.O. et al.

Anexo 1. Continuação...

\begin{tabular}{|c|c|}
\hline Família & Espécie \\
\hline FABACEAE & Indigofera gracilis Spr. \\
\hline FABACEAE & Indigofera suffruticosa Mill. \\
\hline FABACEAE & Inga vera Willd \\
\hline FABACEAE & Lathyrus paranensis Burkart \\
\hline FABACEAE & Leucochloron incuriale (Vell.) Barneby \& Grimes \\
\hline FABACEAE & Lonchocarpus campestris Mart. ex Benth. \\
\hline FABACEAE & Lupinus attenuatus Gardner \\
\hline FABACEAE & Lupinus gibertianus C.P. Sm. \\
\hline FABACEAE & Lupinus guaraniticus (Hassler) C P Sm \\
\hline FABACEAE & Lupinus paraguariensis Chodat \& Hassl. \\
\hline FABACEAE & Lupinus paranensis C.P. Sm. \\
\hline FABACEAE & Lupinus sellowianus Harms \\
\hline FABACEAE & Machaerium aculeatum Raddi \\
\hline FABACEAE & Machaerium acutifolium var enneandrum (Hoehne) Rudd \\
\hline FABACEAE & Machaerium acutifolium Vogel \\
\hline FABACEAE & Machaerium brasiliense Vogel \\
\hline FABACEAE & Machaerium hirtum (Vell.) Stellfeld \\
\hline FABACEAE & Machaerium stipitatum (DC) Vogel \\
\hline FABACEAE & Macroptilium erythroloma (Mart. ex Benth.) Urban \\
\hline FABACEAE & Macroptilium prostratum (Benth.) Urb. \\
\hline FABACEAE & Mimosa bifurca Benth. Var. reducta (Hassl.) Barneby \\
\hline FABACEAE & Mimosa brevipes Butls \\
\hline FABACEAE & Mimosa callosa Benth. \\
\hline FABACEAE & Mimosa daleoides Benth. \\
\hline FABACEAE & Mimosa debilis Humb \& Bonpl ex Wild \\
\hline FABACEAE & Mimosa diplotricha $\mathrm{C}$. Wrigth \\
\hline FABACEAE & Mimosa dolens subsp. acerba Barn. Var. acerba \\
\hline FABACEAE & Mimosa dolens subsp. acerba var. latifolia(Benth.) Barneby \\
\hline FABACEAE & Mimosa dolens subsp. callosa(Benth.) Barn. \\
\hline FABACEAE & Mimosa dolens subsp. rigida(Benth.) Barn. \\
\hline FABACEAE & Mimosa dolens var foliolosa (Benth) Barn. \\
\hline FABACEAE & Mimosa dolens var rudis (Beth) Barn. \\
\hline FABACEAE & Mimosa dolens Vell. subsp. acerba (Benth.) Barneby var. rudis \\
\hline FABACEAE & Mimosa dolens Vell. subsp. acerba (Benth.) Barneby var. uncta \\
\hline FABACEAE & Mimosa dolens Vell. subsp. dolens var. dolens \\
\hline FABACEAE & Mimosa dolens Vell. subsp. eriophylla (Benth.) Barneby \\
\hline FABACEAE & Mimosa dolens Vell. subsp. rigida (Benth.) Barn. var. foliosa \\
\hline FABACEAE & Mimosa dolens Vell. subsp. rigida (Benth.) Barn. var. rigescens (Benth.) Barn. \\
\hline FABACEAE & Mimosa falcipinna Benth. \\
\hline FABACEAE & Mimosa furfuraceae Benth. \\
\hline FABACEAE & Mimosa gracilis subsp. filiformis var. leiocarpa(Burkart) Barneby \\
\hline FABACEAE & Mimosa gracilis var. capillipes (Benth.) Barn. \\
\hline FABACEAE & Mimosa gymnas Barn. \\
\hline FABACEAE & Mimosa hilariana Barneby \\
\hline FABACEAE & Mimosa iperoensis Hoehne var. iperoensis \\
\hline FABACEAE & Mimosa lanata Benth \\
\hline FABACEAE & Mimosa microcarpa Benth \\
\hline FABACEAE & Mimosa micropteris Benth var. micropteris \\
\hline FABACEAE & Mimosa micropteris var. pungens (Burk.) Barn. \\
\hline FABACEAE & Mimosa orthoacantha Benth. \\
\hline FABACEAE & Mimosa paraguariae Micheli var. paraguariae \\
\hline FABACEAE & Mimosa paranapiacabae Barneby \\
\hline FABACEAE & Mimosa petiolaris Benth. \\
\hline FABACEAE & Mimosa pilulifera var. pseudincana (Burk.) Barn. \\
\hline FABACEAE & Mimosa pseudotrachycarpa Barneby \\
\hline FABACEAE & Mimosa ramosissima Benth. \\
\hline FABACEAE & Mimosa reduviosa Barneby \\
\hline FABACEAE & Mimosa regnelli Benth \\
\hline FABACEAE & Mimosa regnellii Benth. var. exuta \\
\hline FABACEAE & Mimosa regnellii Benth. var. grossisetae \\
\hline
\end{tabular}


Anexo 1. Continuação...

\begin{tabular}{|c|c|}
\hline Família & Espécie \\
\hline FABACEAE & Mimosa regnellii Benth. var. supersetosa \\
\hline FABACEAE & Mimosa xanthocentra Mart. subsp. subsericea (Benth.) Barn \\
\hline FABACEAE & Ormosia arborea (Vell.) Harms \\
\hline FABACEAE & Periandra mediterranea (Vell) Taub \\
\hline FABACEAE & Phaseolus obliquifolius Mart. ex Benth. \\
\hline FABACEAE & Phaseolus prostratus Benth. var. angustifolius Benth \\
\hline FABACEAE & Pithecellobium langsdorffii Benth. \\
\hline FABACEAE & Platypodium elegans Vogel \\
\hline FABACEAE & Poiretia angustifolia Vogel \\
\hline FABACEAE & Poiretia latifolia Vogel \\
\hline FABACEAE & Rhynchosia arenicola Hassl. \\
\hline FABACEAE & Rhynchosia corylifolia Mart \\
\hline FABACEAE & Rhynchosia melanocarpa Grear \\
\hline FABACEAE & Rhynchosia minima $(\mathrm{L}) \mathrm{DC}$ \\
\hline FABACEAE & Senna hirsuta var. puberula H.S. Irwin \&Barn. \\
\hline FABACEAE & Senna pendula (Humb. Ex Bonpl. Ex Wild) I. et B. \\
\hline FABACEAE & Senna pilifera (Vogel) H.S. Irwin \& Barneby \\
\hline FABACEAE & Senna rugosa (G Don) H S Irwin \& Barneby \\
\hline FABACEAE & Senna splendida (Vog.) H. S. Irwin \& Barneby \\
\hline FABACEAE & Sthylosanthes acuminata M.B. Ferr \& S. Costa \\
\hline FABACEAE & Stryphnodendron adstringens (Mart.) Coville \\
\hline FABACEAE & Stylosanthes bracteata Vogel \\
\hline FABACEAE & Stylosanthes campestris M B Ferreira \& S Costa \\
\hline FABACEAE & Stylosanthes gracilis Kunth \\
\hline FABACEAE & Stylosanthes guianensis (Aubl.) Sw. \\
\hline FABACEAE & Stylosanthes hippocampoides Mohlenbr \\
\hline FABACEAE & Stylosanthes juncea Micheli \\
\hline FABACEAE & Stylosanthes linearifolia M.B. Ferreira \& S. Costa \\
\hline FABACEAE & Stylosanthes montevidensis Vogel \\
\hline FABACEAE & Stylosanthes nunoii Brandão \\
\hline FABACEAE & Tephrosia rufescens Benth \\
\hline FABACEAE & Teramnus uncinatus (L.) Sw. \\
\hline FABACEAE & var. disadena (Steud.) I. \& B. \\
\hline FABACEAE & Vicia setifolia Kunth \\
\hline FABACEAE & Vigna linearis (Kunth) Maréchal, Mascherpa \&Stainier \\
\hline FABACEAE & Vigna peduncularis (Kunth) Fawc. \& Rendle var. peduncularis \\
\hline FABACEAE & Vigna peduncularis var. clitorioides (Mart. Ex Benth.) Maréchal, Mascherpa \& Stainier \\
\hline FABACEAE & Vigna vexillata $(\mathrm{L}$.$) A. Rich.$ \\
\hline FABACEAE & Zornia burkartii Vanni \\
\hline FABACEAE & Zornia cryptantha Arechav \\
\hline FABACEAE & Zornia cryptantha var. latibracteata Vanni \\
\hline FABACEAE & Zornia dyphyla (L.) Pers \\
\hline FABACEAE & Zornia gemella Vogel \\
\hline FABACEAE & Zornia latifolia $\mathrm{Sm}$ \\
\hline FABACEAE & Zornia latifolia Smith var. criptantha \\
\hline FABACEAE & Zornia ramboiana Mohlenbr. \\
\hline FABACEAE & Zornia reticulata $\mathrm{Sm}$. \\
\hline GENTIANACEAE & Calolisianthus pedunculatus (Cham. \& Schltdl.) Gilg \\
\hline GENTIANACEAE & Curtia conferta (Mart.) Knobl. \\
\hline GENTIANACEAE & Helia brevifolia Cham. \\
\hline GENTIANACEAE & Irlbachia oblongifolia (Mart.) Maas \\
\hline GENTIANACEAE & Tetrapollinia caerulescens (Aubl.) Maguire \&B.M. Boom \\
\hline GENTIANACEAE & Voyria aphylla (Jacq.) Pers. \\
\hline GENTIANACEAE & Zygostigma australe (Cham. \& Schltdl.) Griseb. \\
\hline GESNERIACEAE & Sinningia allagophylla (Mart) Maas \\
\hline GESNERIACEAE & Sinningia canescens (Mart) Wiehler \\
\hline GESNERIACEAE & Sinningia elatior (Kunth) Chautems \\
\hline GESNERIACEAE & Sinningia macropoda (Sprague) \\
\hline GLEICHENIACEAE & Dicranopteris flexuosa (Schrad.) Underw \\
\hline GLEICHENIACEAE & Dicranopteris linearis (Burm f.) Underw \\
\hline
\end{tabular}


Anexo 1. Continuação...

\begin{tabular}{|c|c|}
\hline Família & Espécie \\
\hline GLEICHENIACEAE & Dicranopteris nervosa (Kaulf.) Maxon \\
\hline GLEICHENIACEAE & Dicranopteris pectinata \\
\hline GLEICHENIACEAE & Sticherus bifidus (Willd.) Ching \\
\hline GLEICHENIACEAE & Sticherus penniger (Mart.) Copel \\
\hline HALORAGACEAE & Laurembergia tetrandra (Schott ex Spreng.) Kanitz \\
\hline HYPERICACEAE & Hypericum brasiliensis Choisy \\
\hline HYPERICACEAE & Hypericum caprifoliatum Cham \& Schltdl \\
\hline HYPERICACEAE & Hypericum connatum Lam. \\
\hline HYPERICACEAE & Hypericum cordatum (Vell.) N. Robson var.cordatum \\
\hline HYPERICACEAE & Hypericum cordatum subsp. kleinii N. Robson \\
\hline HYPERICACEAE & Hypericum denudatum A. St.-Hil. \\
\hline HYPERICACEAE & Hypericum piriai Arechav. \\
\hline HYPERICACEAE & Hypericum ternum A. St.-Hil. \\
\hline HYPERICACEAE & Hypericum teretiusculum A. St Hil \\
\hline HYPOXIDACEAE & Hypoxis decumbens $\mathrm{L}$ \\
\hline IRIDACEAE & Calydorea campestris Baker \\
\hline IRIDACEAE & Gelasine coerulea (Vell.) Ravenna \\
\hline IRIDACEAE & Sisyrinchium brasiliensis (Ravenna) Ravenna \\
\hline IRIDACEAE & Sisyrinchium commutatum Klatt \\
\hline IRIDACEAE & Sisyrinchium densiflorum Ravenna \\
\hline IRIDACEAE & Sisyrinchium fasciculatum Klatt \\
\hline IRIDACEAE & Sisyrinchium hoehnei I.M. Johnst. \\
\hline IRIDACEAE & Sisyrinchium iridifolium Kunth \\
\hline IRIDACEAE & Sisyrinchium luzula Klotzsch \\
\hline IRIDACEAE & Sisyrinchium nidulare (Hand. Mazz.) I.M. \\
\hline IRIDACEAE & Sisyrinchium palmifolium $\mathrm{L}$. \\
\hline IRIDACEAE & Sisyrinchium purpurellum subsp. trichospathumRavenna \\
\hline IRIDACEAE & Sisyrinchium restioides Spreng \\
\hline IRIDACEAE & Sisyrinchium vaginatum $\mathrm{Spr}$ \\
\hline IRIDACEAE & Sisyrinchium wettsteinii Hand Mazz \\
\hline IRIDACEAE & Trimezia juncifolia (Klatt) Benth \\
\hline IRIDACEAE & Trimezia spathata subsp. martii (Baker) Ravenna \\
\hline IRIDACEAE & Trimezia spathata Baker subsp. spathata \\
\hline IRIDACEAE & Watsonia meriana (L.) Mill. \\
\hline JUNCACEAE & Juncus andersonii Buchenau \\
\hline JUNCACEAE & Juncus densiflorus Kunth \\
\hline JUNCACEAE & Juncus leersii T. Marsson \\
\hline JUNCACEAE & Juncus micranthus Schrad. ex E. Mey. \\
\hline JUNCACEAE & Juncus microcephalus $\mathrm{HBK}$ \\
\hline JUNCACEAE & Juncus microcephalus var. intermedius E. Mey \\
\hline JUNCACEAE & Juncus micranthus Schrader ex E. Mey. \\
\hline JUNCACEAE & Juncus sellowianus Kunth \\
\hline LAMIACEAE & Aegiphila klotskiana Cham \\
\hline LAMIACEAE & Aegiphila paraguariensis Brig \\
\hline LAMIACEAE & Aegiphila sellowiana Cham. \\
\hline LAMIACEAE & Aegiphila splendens Schauer \\
\hline LAMIACEAE & Aegiphila vericillata Vell. \\
\hline LAMIACEAE & Cunila galioides Benth. \\
\hline LAMIACEAE & Eriope crassipes Benth. \\
\hline LAMIACEAE & Eriope macrostachya Mart e Benth \\
\hline LAMIACEAE & Glechon ciliata Benth \\
\hline LAMIACEAE & Hypenia glauca (St. Hil. ex Benth.) Harley(=Hyptis glauca) \\
\hline LAMIACEAE & Hypenia macrantha (St. Hil. Ex Benth.) Harley (= Hyptis macrantha) \\
\hline LAMIACEAE & Hyptis alata subsp. rugulosa (Briq.) Harley \\
\hline LAMIACEAE & Hyptis althaeifolia Pohl ex Benth. \\
\hline LAMIACEAE & Hyptis apertiflora Epling \\
\hline LAMIACEAE & Hyptis caespitosa A St Hil ex Benth \\
\hline LAMIACEAE & Hyptis elegans Briq. ex Micheli \\
\hline LAMIACEAE & Hyptis imitans Epling \\
\hline LAMIACEAE & Hyptis marrubioides Epling \\
\hline
\end{tabular}


Anexo 1. Continuação...

\begin{tabular}{|c|c|}
\hline Família & Espécie \\
\hline LAMIACEAE & Hyptis plectranthoides Benth \\
\hline LAMIACEAE & Hyptis sinuata Pohl ex Benth. \\
\hline LAMIACEAE & Hyptis suaveolens (L.) \\
\hline LAMIACEAE & Hyptis stricta Benth \\
\hline LAMIACEAE & Ocimum nudicaule Benth. \\
\hline LAMIACEAE & Ocimum selloi Benth. \\
\hline LAMIACEAE & Peltodon longipes Kunth ex Benth. \\
\hline LAMIACEAE & Peltodon radicans Pohl \\
\hline LAMIACEAE & Peltodon rugosus Tolm \\
\hline LAMIACEAE & Peltodon tomentosus Pohl \\
\hline LAMIACEAE & Rhabdocaulon gracile (Benth.) Epling \\
\hline LAMIACEAE & Rhabdocaulon lavanduloides (Benth) Epling \\
\hline LAMIACEAE & Salvia aliciae E.P. Santos \\
\hline LAMIACEAE & Salvia lachnostachys Benth. \\
\hline LAMIACEAE & Salvia melissaeflora Benth. \\
\hline LAMIACEAE & Salvia minarum Briq. \\
\hline LAMIACEAE & Salvia nervosa Benth. \\
\hline LAMIACEAE & Salvia rosmarinoides A. St.-Hil. ex Benth. \\
\hline LAMIACEAE & Scutelaria racemosa Pers \\
\hline LAURACEAE & Aiouea trinervis Meisn \\
\hline LAURACEAE & Cinnamomum sellowianum (Nees \& C. Martius ex Nees) Kost. \\
\hline LAURACEAE & Cryptocarya aschersoniana $\mathrm{Mez}$ \\
\hline LAURACEAE & Nectandra grandiflora Nees \& Mart. ex Nees \\
\hline LAURACEAE & Nectandra lanceolata Ness \\
\hline LAURACEAE & Ocotea corymbosa (meissn.) Mez \\
\hline LAURACEAE & Ocotea diospyrifolia (Meisn.) Mez \\
\hline LAURACEAE & Ocotea lancifolia (Schott) Mez \\
\hline LAURACEAE & Ocotea odorifera (Vellozo) Rohwer \\
\hline LAURACEAE & Ocotea porosa (Nees) Barroso \\
\hline LAURACEAE & Ocotea pulchella Mart \\
\hline LAURACEAE & Ocotea tristis (Nees) Mez \\
\hline LAURACEAE & Persea alba Nees \\
\hline LAURACEAE & Persea fulva Kopp var. fulva \\
\hline LAURACEAE & Persea major Kopp \\
\hline LAURACEAE & Persea venosa Nees \& Mart ex Nees \\
\hline LENTIBULARIACEAE & Genlisea repens Benj. \\
\hline LENTIBULARIACEAE & Utricularia dusenii Sylven \\
\hline LENTIBULARIACEAE & Utricularia flaccida A.DC. \\
\hline LENTIBULARIACEAE & Utricularia gibba $\mathrm{L}$ \\
\hline LENTIBULARIACEAE & Utricularia laxa St. Hilaire \& Girard \\
\hline LENTIBULARIACEAE & Utricularia nana A St Hil \& F Girard \\
\hline LENTIBULARIACEAE & Utricularia praelonga St. Hil. \& Girard \\
\hline LENTIBULARIACEAE & Utricularia reniformis St. Hil. \\
\hline LENTIBULARIACEAE & Utricularia tricolor A St Hil \\
\hline LENTIBULARIACEAE & Utricularia triloba Renj. \\
\hline LINACEAE & Linum brevifolium St. Hil. \& Naud. \\
\hline LINACEAE & Linum littorale St. Hil. \\
\hline LOGANIACEAE & Spigelia blanchetiana DC \\
\hline LOGANIACEAE & Strychnos brasiliensis Mart. \\
\hline LOGANIACEAE & Strychnos rubiginosa DC. \\
\hline LORANTHACEAE & Strutanthus concinus \\
\hline LYCOPODIACEAE & Huperzia fontinaloides (Spring) Trevis \\
\hline LYCOPODIACEAE & Huperzia reflexa (Lam.) Trevis \\
\hline LYCOPODIACEAE & Lycopodiella alopecuroides (1.) Cranfill \\
\hline LYCOPODIACEAE & Lycopodiella cernua (L.) Pic Serm. \\
\hline LYCOPODIACEAE & Lycopodiella carolinia (L.) Pic Serm. \\
\hline LYCOPODIACEAE & Lycopodium clavatum $\mathrm{L}$. \\
\hline LYCOPODIACEAE & Lycopodium thyoides Humb. \& Bonpl. ex Willd. \\
\hline LYTHRACEAE & Cuphea acinifolia St. Hil. \\
\hline LYTHRACEAE & Cuphea calophylla Cham. \& Schltdl. subsp. mesostemon (Koehne) Lourteig \\
\hline
\end{tabular}


Anexo 1. Continuação...

\begin{tabular}{|c|c|}
\hline Família & Espécie \\
\hline LYTHRACEAE & Cuphea carthagenensis (Jacq.) J. F. Macbr \\
\hline LYTHRACEAE & Cuphea confertiflora A. St.-Hil. \\
\hline LYTHRACEAE & Cuphea glutinosa Cham. \& Schltdl. \\
\hline LYTHRACEAE & Cuphea linarioides Cham. \& Schltdl \\
\hline LYTHRACEAE & Cuphea lindmaniana Koehne et Bak. \\
\hline LYTHRACEAE & Cuphea linifolia (A. St Hil) Koehne \\
\hline LYTHRACEAE & Cuphea polymorpha A. St.-Hil. \\
\hline LYTHRACEAE & Cuphea racemosa (L.) Spr. \\
\hline LYTHRACEAE & Cuphea strigulosa Kunth \\
\hline LYTHRACEAE & Cuphea thymoides Cham. \& Schltdl \\
\hline LYTHRACEAE & Cuphea thymoides var. saturejoidesA. St.-Hil. \\
\hline LYTHRACEAE & Cuphea varia Koehne ex Bacig. \\
\hline LYTHRACEAE & Heimia myrtifolia Cham. \& Schltdl. \\
\hline LYTHRACEAE & Lafoensia densiflora Pohl \\
\hline LYTHRACEAE & Lafoensia nummularifolia A. St- Hil. \\
\hline LYTHRACEAE & Lafoensia pacari A. St Hill \\
\hline MAGNOLIACEAE & Talauma ovata A.St.-Hil. \\
\hline MALPIGHIACEAE & Aspicarpa argentea var. sericea (Griseb.) Nied. \\
\hline MALPIGHIACEAE & Aspicarpa pulchella (Griseb.) O’Donell \& Lourteig \\
\hline MALPIGHIACEAE & Banisteriopsis adenopoda (A. Juss.) B. Gates \\
\hline MALPIGHIACEAE & Banisteriopsis campestris (A Juss) Little \\
\hline MALPIGHIACEAE & Byrsonima brachybotrya Nied. \\
\hline MALPIGHIACEAE & Byrsonima clausseniana A Juss \\
\hline MALPIGHIACEAE & Byrsonima coccolobifolia Kunth. \\
\hline MALPIGHIACEAE & Byrsonima crassifolia Steud \\
\hline MALPIGHIACEAE & Byrsonima cydoniaefolia A Juss \\
\hline MALPIGHIACEAE & Byrsonima guilleminiana A. Juss. \\
\hline MALPIGHIACEAE & Byrsonima intermedia Juss \\
\hline MALPIGHIACEAE & Byrsonima psilandra Griseb. \\
\hline MALPIGHIACEAE & Byrsonima verbascifolia (L.) Rich. ex Juss \\
\hline MALPIGHIACEAE & Camarea affinis A St Hill \\
\hline MALPIGHIACEAE & Heteropterys byrsonimifolia A. Juss \\
\hline MALPIGHIACEAE & Heteropterys campestris A. Juss. \\
\hline MALPIGHIACEAE & Heteropterys dusenii Nied. \\
\hline MALPIGHIACEAE & Heteropterys pauciflora A. Juss. \\
\hline MALPIGHIACEAE & Heteropterys syringifolia Griseb \\
\hline MALPIGHIACEAE & Heteropterys umbellata A. Juss. \\
\hline MALPIGHIACEAE & Heteropterys xantophylla A.Juss. \\
\hline MALPIGHIACEAE & Peixotoa parviflora Adr. Juss. \\
\hline MALPIGHIACEAE & Peixotoa reticulata Griseb \\
\hline MALPIGHIACEAE & Peregrina linearifolia (A. St.-Hil.) W.R.Anderson \\
\hline MALPIGHIACEAE & Tetrapteris salicifolia Nied. \\
\hline MALVACEAE & Bombax endecaphyllum Vell. \\
\hline MALVACEAE & Byttneria hatschbachii Cristobal \\
\hline MALVACEAE & Byttneria scabra L. \\
\hline MALVACEAE & Byttneria scalpellata Pohl \\
\hline MALVACEAE & Chorisia speciosa A. St Hil \\
\hline MALVACEAE & Eriotheca gracilipes (K. Schum) A. Robyns \\
\hline MALVACEAE & Guazuma ulmifolia Lam. \\
\hline MALVACEAE & Krapovickasia macrodon (DC.) Fryxell (= Sida macrodon) \\
\hline MALVACEAE & Luehea candicans Mart \\
\hline MALVACEAE & Luehea divaricata Mart. \\
\hline MALVACEAE & Luehea grandiflora Mart \\
\hline MALVACEAE & Melochia pilosa (Mill.) Fawc. \& Rendle \\
\hline MALVACEAE & Melochia tomentosa (L.) Mioto \\
\hline MALVACEAE & Pavonia commutata Gürke \\
\hline MALVACEAE & Pavonia communis A. St.-Hil. \\
\hline MALVACEAE & Pavonia exserta Krapov. \& Cristóbal \\
\hline MALVACEAE & Pavonia gamophylla Krapov. \& Cristóbal \\
\hline MALVACEAE & Pavonia guerkeana R. E. Fr \\
\hline
\end{tabular}


Anexo 1. Continuação...

\begin{tabular}{|c|c|}
\hline Família & Espécie \\
\hline MALVACEAE & Pavonia hastata Cav. \\
\hline MALVACEAE & Pavonia laxifolia A. St. Hil. \\
\hline MALVACEAE & Pavonia schrankii Spreng. \\
\hline MALVACEAE & Pavonia sepium A. St.-Hil. \\
\hline MALVACEAE & Peltaea edoaurdii (Hochr) Krapov \& Cristobal \\
\hline MALVACEAE & Peltaea polymorpha A St Hill Krapov \& Cristobal \\
\hline MALVACEAE & Peltaea speciosa (Kunth) Standl. \\
\hline MALVACEAE & Pseudobombax grandiflorum (Cav.) A. Robyns \\
\hline MALVACEAE & Sida cerradoensis Krapov \\
\hline MALVACEAE & Sida cordifolia $\mathrm{L}$ \\
\hline MALVACEAE & Sida glaziovii K. Schum \\
\hline MALVACEAE & Sida linifolia $\mathrm{Cav}$ \\
\hline MALVACEAE & Sida rhombifolia Krap. \\
\hline MALVACEAE & Sida santaremensis Monteiro \\
\hline MALVACEAE & Sida ulei Ulbr. \\
\hline MALVACEAE & Sida viarum A. St.-Hil. \\
\hline MALVACEAE & Waltheria carpinifolia A St Hil \\
\hline MALVACEAE & Waltheria communis A. St.-Hil. \\
\hline MALVACEAE & Waltheria douradinha A St Hil \\
\hline MALVACEAE & Waltheria cf. polyantha K. Schum \\
\hline MALVACEAE & Waltheria indica $\mathrm{L}$ \\
\hline MARCRAVIACEAE & Marcgravia poliantha Delp. \\
\hline MELASTOMATACEAE & Acisanthera alsinaefolia (DC.) Triana \\
\hline MELASTOMATACEAE & Acisanthera variabilis (DC) Triana \\
\hline MELASTOMATACEAE & Cambessedesia espora (DC.) subsp. ilicifolia (DC.) A.B. Martins \\
\hline MELASTOMATACEAE & Chaetostoma pungens DC. \\
\hline MELASTOMATACEAE & Lavoisiera phyllocalycina Cogn. \\
\hline MELASTOMATACEAE & Lavoisiera pulchella Cham \\
\hline MELASTOMATACEAE & Leandra acutiflora (Naudin) Cogn. \\
\hline MELASTOMATACEAE & Leandra aurea Cogn \\
\hline MELASTOMATACEAE & Leandra acutiflora (Naudin) Cogn. \\
\hline MELASTOMATACEAE & Leandra debilis Cogn. \\
\hline MELASTOMATACEAE & Leandra dusenii Cogn. \\
\hline MELASTOMATACEAE & Leandra erostrata (DC.) Cogn. \\
\hline MELASTOMATACEAE & Leandra foveolata Cogn. \\
\hline MELASTOMATACEAE & Leandra gracilis Cogn. \\
\hline MELASTOMATACEAE & Leandra lacunosa Cogn. \\
\hline MELASTOMATACEAE & Leandra laevigata (Triana) Cogn. \\
\hline MELASTOMATACEAE & Leandra melastomoides Raddi \\
\hline MELASTOMATACEAE & Leandra microphylla Cogn. \\
\hline MELASTOMATACEAE & Leandra polystachya (Naudin) Cogn. \\
\hline MELASTOMATACEAE & Leandra pubescens Cogn. \\
\hline MELASTOMATACEAE & Leandra purpurascens (DC) Cogn \\
\hline MELASTOMATACEAE & Leandra refracta Cogn. \\
\hline MELASTOMATACEAE & Leandra regnelli (Triana) Cogn. \\
\hline MELASTOMATACEAE & Leandra scabra DC \\
\hline MELASTOMATACEAE & Miconia albicans (SW) Triana \\
\hline MELASTOMATACEAE & Miconia chamissois Naudin \\
\hline MELASTOMATACEAE & Miconia cinerascens Miq. \\
\hline MELASTOMATACEAE & Miconia doriana Cogn. \\
\hline MELASTOMATACEAE & Miconia elegans Cogn \\
\hline MELASTOMATACEAE & Miconia hyemalis St Hill \& Naud ex Naud \\
\hline MELASTOMATACEAE & Miconia ligustroides (DC) Naudin \\
\hline MELASTOMATACEAE & Miconia petropolitana $\operatorname{Cogn}$ \\
\hline MELASTOMATACEAE & Miconia sellowiana Naud \\
\hline MELASTOMATACEAE & Miconia stenostachya A. DC \\
\hline MELASTOMATACEAE & Miconia theaezans (Bonpl.) Cogn. \\
\hline MELASTOMATACEAE & Microlepis oleifolia (DC.) Triana \\
\hline MELASTOMATACEAE & Pterolepis repanda (DC) Triana \\
\hline MELASTOMATACEAE & Rhynchanthera brachyrhyncha Cham. \\
\hline
\end{tabular}


Anexo 1. Continuação...

\begin{tabular}{|c|c|}
\hline Família & Espécie \\
\hline MELASTOMATACEAE & Tibouchina cerastifolia Cogn \\
\hline MELASTOMATACEAE & Tibouchina chamissoana Cogn \\
\hline MELASTOMATACEAE & Tibouchina debilis (Cham.) Cogn. \\
\hline MELASTOMATACEAE & Tibouchina dubia Cham (Cogn) \\
\hline MELASTOMATACEAE & Tibouchina gracilis (Bonpl.) Cogn. \\
\hline MELASTOMATACEAE & Tibouchina grandifolia Cogn. \\
\hline MELASTOMATACEAE & Tibouchina hatschbachii Wurdack \\
\hline MELASTOMATACEAE & Tibouchina herincquiana Cogn \\
\hline MELASTOMATACEAE & Tibouchina martialis (Cham) Cogn \\
\hline MELASTOMATACEAE & Tibouchina pauciflora Cogn. \\
\hline MELASTOMATACEAE & Tibouchina rupestris Cogn. \\
\hline MELASTOMATACEAE & Tibouchina sellowiana Cogn \\
\hline MELASTOMATACEAE & Tibouchina stenocarpa (DC.) Cogn \\
\hline MELASTOMATACEAE & Tibouchina ursina (Cham) Cogn \\
\hline MELASTOMATACEAE & Trembleya parviflora (D. Don) Cogn. \\
\hline MELASTOMATACEAE & Trembleya phlogiformis DC \\
\hline MELIACEAE & Cabralea canjerana (Don.) Cogn \\
\hline MELIACEAE & Cedrela fissilis (Vell.) Mart. \\
\hline MENISPERMACEAE & Cissampelos cf. andromorpha DC \\
\hline MENISPERMACEAE & Cissampelos ovalifolia DC \\
\hline MORACEAE & Brosimum gaudichaudii Trécul \\
\hline MORACEAE & Dorstenia brasiliensis Lam. \\
\hline MORACEAE & Ficus enormis (Mart. ex Miq.) Miq. \\
\hline MYRTACEAE & Blepharocalyx salicifolius (Humb., Bonpl. \& Kunth) Berg \\
\hline MYRTACEAE & Blepharocalyx umbilicata (Cambess.) Burret \\
\hline MYRTACEAE & Calyptranthes concinna DC \\
\hline MYRTACEAE & Campomanesia adamantium (Camb.) O. Berg \\
\hline MYRTACEAE & Campomanesia aurea var. hatschbachii(Mattos) Legr. \\
\hline MYRTACEAE & Campomanesia cambessedeana $\mathrm{O}$. Berg \\
\hline MYRTACEAE & Campomanesia campestris (Cambess.) D.Legr. \\
\hline MYRTACEAE & Campomanesia guazumaefolia (Camb.) O.Berg \\
\hline MYRTACEAE & Campomanesia pubescens (A DC) O Berg \\
\hline MYRTACEAE & Campomanesia xanthocarpa O. Berg \\
\hline MYRTACEAE & Eugenia arenosa Mattos \\
\hline MYRTACEAE & Eugenia bimarginata DC \\
\hline MYRTACEAE & Eugenia dysenterica DC. \\
\hline MYRTACEAE & Eugenia florida DC. \\
\hline MYRTACEAE & Eugenia hiemalis Cambess \\
\hline MYRTACEAE & Eugenia jaguariaivensis Mattos \\
\hline MYRTACEAE & Eugenia obtusifolia Cambess. \\
\hline MYRTACEAE & Eugenia obversa O. Berg. \\
\hline MYRTACEAE & Eugenia pitanga (O. Berg ex Mart.) Kiaersk \\
\hline MYRTACEAE & Eugenia pluriflora DC. \\
\hline MYRTACEAE & Eugenia punicifolia Kunth DC \\
\hline MYRTACEAE & Eugenia pyriformis Cambess. var. uvalha (Cambess.) Legr. \\
\hline MYRTACEAE & Eugenia pyriformis Cambess. var. argentea Mattos \& Legr. \\
\hline MYRTACEAE & Eugenia suberosa $\mathrm{Camb}$ \\
\hline MYRTACEAE & Eugenia suffrutescens Nied. \\
\hline MYRTACEAE & Gomidesia sellowiana O. Berg. \\
\hline MYRTACEAE & Hexachlamys edulis (O.Berg) Legr. \& Kauss. \\
\hline MYRTACEAE & Hexachlamys hamiltonii Mattos \\
\hline MYRTACEAE & Hexachlamys humilis O.Berg \\
\hline MYRTACEAE & Hexachlamys itatiaiensis Mattos \\
\hline MYRTACEAE & Myrceugenia alpigena (DC.) Landrum \\
\hline MYRTACEAE & Myrceugenia alpigena (DC.) Landrum var. rufa \\
\hline MYRTACEAE & Myrceugenia bracteosa (DC.) D. Legrand \& Kausel \\
\hline MYRTACEAE & Myrceugenia hatschbachii Landrum \\
\hline MYRTACEAE & Myrceugenia myrcioides (Cambess.) O. Berg \\
\hline MYRTACEAE & Myrceugenia ovata var. regnelliana (O. Berg)Landrum \\
\hline MYRTACEAE & Myrceugenia oxysepala (Burret) D. Legrand \& Kausel \\
\hline
\end{tabular}


Anexo 1. Continuação...

\begin{tabular}{|c|c|}
\hline Família & Espécie \\
\hline MYRTACEAE & Myrcia anomala Cambess. \\
\hline MYRTACEAE & Myrcia arborescens O. Berg \\
\hline MYRTACEAE & Myrcia breviramis (O. Berg) D. Legr. \\
\hline MYRTACEAE & Myrcia castrensis (O. Berg.) Legr. \\
\hline MYRTACEAE & Myrcia fallax (Rich.) DC. \\
\hline MYRTACEAE & Myrcia floribunda Miq \\
\hline MYRTACEAE & Myrcia jaguariaivensis Mattos \\
\hline MYRTACEAE & Myrcia multiflora (Lam.) DC. \\
\hline MYRTACEAE & Myrcia obtecta (Berg) Kiaresk \\
\hline MYRTACEAE & Myrcia palustris DC. \\
\hline MYRTACEAE & Myrcia rostrata DC. \\
\hline MYRTACEAE & Myrcia tomentosa DC. \\
\hline MYRTACEAE & Myrcia venulosa DC. \\
\hline MYRTACEAE & Myrcia verrucosa \\
\hline MYRTACEAE & Myrciaria ciliolata (Cambess.) O. Berg \\
\hline MYRTACEAE & Myrciaria cuspidata $\mathrm{O}$. Berg \\
\hline MYRTACEAE & Myrciaria delicatula (DC) Berg \\
\hline MYRTACEAE & Myrciaria floribunda (West ex Willd.) Berg \\
\hline MYRTACEAE & Myrciaria tenella (DC.)O.Berg \\
\hline MYRTACEAE & Pimenta pseudocaryophyllus (Gomes) Landrum \\
\hline MYRTACEAE & Psidium australe Cambess \\
\hline MYRTACEAE & Psidium bergianum (Nied.) Burret \\
\hline MYRTACEAE & Psidium cinereum Mart \\
\hline MYRTACEAE & Psidium cinereum var. incanescens (Mart. Ex DC) Legr. \\
\hline MYRTACEAE & Psidium glaucescens O. Berg. \\
\hline MYRTACEAE & Psidium grandiflorum Aubl. \\
\hline MYRTACEAE & Psidium laruotteanum Cambess \\
\hline MYRTACEAE & Psidium luridum (Spreng.) Bur \\
\hline MYRTACEAE & Psidium luridum (Spreng.) Burret var. robusta \\
\hline MYRTACEAE & Psidium multiflorum Camb. \\
\hline MYRTACEAE & Psidium rubescens $\mathrm{O}$. Berg \\
\hline MYRTACEAE & Psidium rufum Mart ex DC \\
\hline MYRTACEAE & Psidium spathulathum Mattos \\
\hline MYRTACEAE & Psidium suffruticosum O.Berg \\
\hline MYRTACEAE & Siphoneugenia widgreniana Berg \\
\hline NYCTAGINACEAE & Guapira opposita Aubl. \\
\hline OCHNACEAE & Ouratea salicifolia Engl \\
\hline OCHNACEAE & Ouratea sellowii (Planch.) Engl. \\
\hline OCHNACEAE & Ouratea semiserrata (Mart \& Nees) Engl \\
\hline OCHNACEAE & Ouratea spectabilis (Mart) Engl \\
\hline OCHNACEAE & Sauvagesia capillaris (St. Hil.) C. Sastre \\
\hline OCHNACEAE & Sauvagesia erecta $\mathrm{L}$ \\
\hline OCHNACEAE & Sauvagesia racemosa A. St Hil \\
\hline OCHNACEAE & Sauvagesia vellozii (Vell.) Reitz \\
\hline ONAGRACEAE & Ludwigia leptocarpa (Nutt) H. Hara \\
\hline ONAGRACEAE & Ludwigia longifolia (DC.) H. Hara \\
\hline ONAGRACEAE & Ludwigia martii (Micheli) Ramamoorthy \\
\hline ONAGRACEAE & Ludwigia nervosa (Poir.) H. Hara \\
\hline ONAGRACEAE & Ludwigia sericea (Cambess.) Hara \\
\hline ONAGRACEAE & Oenothera affinis Cambess. \\
\hline ONAGRACEAE & Oenothera indecora Cambess. \\
\hline ONAGRACEAE & Oenothera longiflora L. \\
\hline OPILIACEAE & Agonandra englerii Hoehne \\
\hline ORCHIDACEAE & Beadlea graciliscapa (Schltr.) Garay \\
\hline ORCHIDACEAE & Bifrenaria harrisoniae (Hook.) Rchb. f. \\
\hline ORCHIDACEAE & Bulbophyllum jaguariahyvae Kraenzl. \\
\hline ORCHIDACEAE & Bulbophyllum micranthum Hook. f. \\
\hline ORCHIDACEAE & Bulbophyllum plumosum (Barb. Rodr.) Cogn. \\
\hline ORCHIDACEAE & Bulbophyllum punctatum Fitzg \\
\hline ORCHIDACEAE & Cleistes cipoana Hoehne \\
\hline
\end{tabular}


Anexo 1. Continuação...

\begin{tabular}{|c|c|}
\hline Família & Espécie \\
\hline ORCHIDACEAE & Cleistes paranaensis (Barb. Rodr.) Schltr \\
\hline ORCHIDACEAE & Cleites quadricalosa (Barb.Rodr.)Schltr \\
\hline ORCHIDACEAE & Cyanaeorchis arundinae (Rchb. F.) B. Rodr. \\
\hline ORCHIDACEAE & Cyclopogon apricus (Lindl.) Schltr. \\
\hline ORCHIDACEAE & Cyrtopodium brandonianum Barb. Rodr. \\
\hline ORCHIDACEAE & Cyrtopodium dusenii Schltr. \\
\hline ORCHIDACEAE & Cyrtopodium eugenii $\mathrm{Rchb}$. $\mathrm{f}$. \\
\hline ORCHIDACEAE & Cyrtopodium pallidum Rchb. f. \& Warm. \\
\hline ORCHIDACEAE & Epidendrum crassifolium Jacq. \\
\hline ORCHIDACEAE & Epidendrum dendrobioides Thunb. \\
\hline ORCHIDACEAE & Epidendrum denticulatum Barb. Rodr. \\
\hline ORCHIDACEAE & Epidendrum ellipticum Graham \\
\hline ORCHIDACEAE & Epidendrum pseudavicula Kraenzl. \\
\hline ORCHIDACEAE & Epidendrum secundum $\mathrm{Sw}$. \\
\hline ORCHIDACEAE & Epidendron elongatum Jacq \\
\hline ORCHIDACEAE & Epidendron pseudavicoloa Kraenzl. \\
\hline ORCHIDACEAE & Epistephium sclerophyllum Lindl \\
\hline ORCHIDACEAE & Geoblasta pennicillata (Rchb. f.) Hoehne exM.D. Correa \\
\hline ORCHIDACEAE & Gomesa crispa (Lall) Kl. \& Rch f. \\
\hline ORCHIDACEAE & Habenaria armata Rchb. \\
\hline ORCHIDACEAE & Habenaria bractescens Lindl. \\
\hline ORCHIDACEAE & Habenaria fastor Warn \\
\hline ORCHIDACEAE & Habenaria guilleminii Rchb. F. \\
\hline ORCHIDACEAE & Habenaria humilis Cogn \\
\hline ORCHIDACEAE & Habenaria johannensis Barb. Rodr. \\
\hline ORCHIDACEAE & Habenaria macronectar (Vell.) Hoehne \\
\hline ORCHIDACEAE & Habenaria montevidensis var. parviflora (Lindl.) Pabst \\
\hline ORCHIDACEAE & Habenaria montevidensis Spreng \\
\hline ORCHIDACEAE & Habenaria obtusa Lindl \\
\hline ORCHIDACEAE & Habenaria piraquarensis Hoehne \\
\hline ORCHIDACEAE & Habenaria platydactyla Kraenzl \\
\hline ORCHIDACEAE & Habenaria schwackei Barb. Rodr. \\
\hline ORCHIDACEAE & Maxillaria marginata Fenzl \\
\hline ORCHIDACEAE & Maxillaria vernicosa Barb. Rodr. \\
\hline ORCHIDACEAE & Octomeria palmyrabellae Barb. Rodr \\
\hline ORCHIDACEAE & Oncidium blanchetii Rchb. \\
\hline ORCHIDACEAE & Oncidium fuscans Rchb. f. \\
\hline ORCHIDACEAE & Oncidium hydrophilum Barb. Rodr. \\
\hline ORCHIDACEAE & Oncidium pontagrossensis \\
\hline ORCHIDACEAE & Pelexia bonariensis (Lindl.) Schltr. \\
\hline ORCHIDACEAE & Pelexia novofriburgensis (Rchb. f.) Garay \\
\hline ORCHIDACEAE & Pelexia orthosepala (Rchb. f. \& Warm.) Schltr. \\
\hline ORCHIDACEAE & Pelexia orobanchoides (Kraenzl.) Schltr. \\
\hline ORCHIDACEAE & Pelexia pterygantha (Rchb. f. \& Warm.) Schltr. \\
\hline ORCHIDACEAE & Pelexia tamanduensis (Kraenzl.) Schltr. \\
\hline ORCHIDACEAE & Pelexia tenuior Schltr. \\
\hline ORCHIDACEAE & Pleurothallis aveniformis Hoehne \\
\hline ORCHIDACEAE & Pleurothallis caespitosa Barb. Rodr. \\
\hline ORCHIDACEAE & Pleurothallis glossochila Kraenzl. \\
\hline ORCHIDACEAE & Pleurothallis grobyi Bateman ex Lindl. \\
\hline ORCHIDACEAE & Rodriguezia decora (Lem.) Rchb. F \\
\hline ORCHIDACEAE & Sacoila duseniana Garay \\
\hline ORCHIDACEAE & Sacoila hassleri (Cogn.) Garay \\
\hline ORCHIDACEAE & Sacoila lanceolata (Aubl.) Garay \\
\hline ORCHIDACEAE & Sarcoglottis homalogastra (Rchb. f. \& Warm.) Schltr. \\
\hline ORCHIDACEAE & Sarcoglottis neuroptera (Rchb. f. \& Warm.)Schltr. \\
\hline ORCHIDACEAE & Sarcoglottis uliginosa (Barb. Rodr.) Barb. Rodr. \\
\hline ORCHIDACEAE & Skeptrostachys disoides (Kraenzl.) Garay \\
\hline ORCHIDACEAE & Skeptrostachys paraguayensis (Rchb. f.) Garay \\
\hline ORCHIDACEAE & Sophronitella violacea (Lindl.) Schltr. \\
\hline
\end{tabular}


Anexo 1. Continuação...

\begin{tabular}{|c|c|}
\hline Família & Espécie \\
\hline ORCHIDACEAE & Stenorrhynchos arechavaletanii Barb. Rodr. \\
\hline ORCHIDACEAE & Stenorhynchus australis Lindl \\
\hline ORCHIDACEAE & Stenorrhynchos bradei Schltr. \\
\hline ORCHIDACEAE & Stenorrhynchos holosericeum Kraenzl. \\
\hline ORCHIDACEAE & Stenorrhynchos paraguayensis (Rchb. f.) Cogn. \\
\hline ORCHIDACEAE & Stenorrhynchos pedicellatum Cogn. \\
\hline ORCHIDACEAE & Zygopetalum mackaii Hook. \\
\hline ORCHIDACEAE & Wullschlaegelia aphylla \\
\hline OROBANCHACEAE & Agalinis communis (Cham. \& Schltdl.) D'Arcy \\
\hline OROBANCHACEAE & Agalinis genistifolia (Cham. \& Schltdl.) D'Arcy \\
\hline OROBANCHACEAE & Agalinis linarioides (Cham. \& Schltdl.) D'Arcy \\
\hline OROBANCHACEAE & Buchnera integrifolia Larrañaga \\
\hline OROBANCHACEAE & Buchnera juncea Cham. \& Schltdl \\
\hline OROBANCHACEAE & Buchnera longifolia Kunth \\
\hline OROBANCHACEAE & Buchnera ternifolia Kunth \\
\hline OSMUNDACEAE & Osmunda cinnamomea $\mathrm{L}$ \\
\hline OSMUNDACEAE & Osmunda regalis $\mathrm{L}$ \\
\hline OXALIDACEAE & Oxalis conorrhyza Jacq \\
\hline OXALIDACEAE & Oxalis hispidula Zucc \\
\hline OXALIDACEAE & Oxalis myriophylla A St Hil \\
\hline OXALIDACEAE & Oxalis praetexta Progel \\
\hline PASSIFLORACEAE & Passiflora edulis Sims \\
\hline PASSIFLORACEAE & Passiflora haematostigma Mart. \\
\hline PASSIFLORACEAE & Passiflora lepidota Mast \\
\hline PASSIFLORACEAE & Passiflora misera Kunth \\
\hline PASSIFLORACEAE & Passiflora setulosa Killip \\
\hline PASSIFLORACEAE & Passiflora suberosa L. \\
\hline PASSIFLORACEAE & Passiflora villosa Vell. \\
\hline PASSIFLORACEAE & Piriqueta selloi Urb. \\
\hline PASSIFLORACEAE & Piriqueta taubatensis (Urb.) Arbo \\
\hline PENTAPHYLACEAE & Ternstroemia brasiliensis Camb \\
\hline PHYLLANTACEAE & Phyllanthus leptophyllus Müll. Arg. \\
\hline PHYLLANTACEAE & Phyllanthus niruri $\mathrm{L}$. \\
\hline PHYTOLACACEAE & Phytolaca thyrsiflora Fenzl ex Schimdt \\
\hline PIPERACEAE & Peperomia blanda var. pseudo-dindygulensis(C. DC.) Yunck. \\
\hline PIPERACEAE & Peperomia catharinae Miq. \\
\hline PIPERACEAE & Peperomia galioides Kunth \\
\hline PIPERACEAE & Peperomia martiana Miq. \\
\hline PIPERACEAE & Peperomia rubricaulis var parvifolia Yuncker \\
\hline PIPERACEAE & Peperomia trineura Miq. \\
\hline PIPERACEAE & Piper mollicomum Kunth \\
\hline PLANTAGINACEAE & Angelonia integerrima Spreng \\
\hline PLANTAGINACEAE & Gratiola peruviana $\mathrm{L}$. \\
\hline PLANTAGINACEAE & Linaria canadensis $(\mathrm{L}$.$) Dum. Cours.$ \\
\hline PLANTAGINACEAE & Mecardonia dianthera (Sw.) Pennell \\
\hline PLANTAGINACEAE & Mecardonia tenella (Cham. \& Schltdl.) Pennel \\
\hline PLANTAGINACEAE & Plantago australis Lam. \\
\hline PLANTAGINACEAE & Plantago australis subsp. hirtella (Kunth) Rahn \\
\hline PLANTAGINACEAE & Plantago commersoniana Decne. \\
\hline PLANTAGINACEAE & Plantago guilleminiana Decne \\
\hline PLANTAGINACEAE & Plantago hirtella \\
\hline PLANTAGINACEAE & Plantago major L. \\
\hline PLANTAGINACEAE & Plantago tomentosa Lam. \\
\hline PLANTAGINACEAE & Scoparia dulcis $\mathrm{L}$ \\
\hline PLANTAGINACEAE & Scoparia pinnatifida Cham. \& Schltdl. \\
\hline POACEAE & Agenium villosum (Nees) Pilg. \\
\hline POACEAE & Agrostis montevidensis Spreng. ex Nees \\
\hline POACEAE & Andropogon bicornis Forssk \\
\hline POACEAE & Andropogon lateralis $\mathrm{Ne}$ \\
\hline POACEAE & Andropogon leucostachyus Kunth \\
\hline
\end{tabular}


Anexo 1. Continuação...

\begin{tabular}{|c|c|}
\hline Família & Espécie \\
\hline POACEAE & Andropogon macrothrix Trin. \\
\hline POACEAE & Andropogon selloanus Hack \\
\hline POACEAE & Andropogon tener (Nees) Kunth \\
\hline POACEAE & Andropogon virgatus Desv. ex Ham. \\
\hline POACEAE & Anthaenantiopsis trachystachya (Nees) Mez exPilg. \\
\hline POACEAE & Aristida flaccida Trin. \& Rupr. \\
\hline POACEAE & Aristida jubata (Arechav.) Herter \\
\hline POACEAE & Aristida megapotamica Spreng \\
\hline POACEAE & Aristida pallens Cav. \\
\hline POACEAE & Aristida purpurea var longiseta (Steud) Vasey \\
\hline POACEAE & Arundinella brasiliensis Raddi \\
\hline POACEAE & Arundinella hispida (Humb. \& Bonpl. exWilld.) Kuntze \\
\hline POACEAE & Arthropogon villosus Nees \\
\hline POACEAE & Avena fatua $\mathrm{L}$ \\
\hline POACEAE & Axonopus affinis Chase \\
\hline POACEAE & Axonopus barbigerus (Kunth) Hitchc. \\
\hline POACEAE & Axonopus brasiliensis (Spreng) Kuhlm \\
\hline POACEAE & Axonopus compresus (Sw.) P. Beauv. \\
\hline POACEAE & Axonopus fissifolius (Raddi) Kuhlm \\
\hline POACEAE & Axonopus fissifolius var. polystachyus (G.A. Black) L.B. Sm. \& Wassh. \\
\hline POACEAE & Axonopus iridaceus (Mez) Hitchc. \& Chase ex Rojas \\
\hline POACEAE & Axonopus marginatus (Trin.) Chase \\
\hline POACEAE & Axonopus pressus (Nees es Steud) Vasey \\
\hline POACEAE & Axonpous siccus (Nees) Kuhlm \\
\hline POACEAE & Axonopus suffultus (Mikan ex Trin.) Parodi \\
\hline POACEAE & Axonopus ulei (Hack.) Dedecca \\
\hline POACEAE & Brachiaria decumbens Stapf \\
\hline POACEAE & Brachiaria plantaginea (Link) Hitchc. \\
\hline POACEAE & Briza calotheca (Trin) Hack \\
\hline POACEAE & Briza uniolae (Nees) Nees ex Steud. \\
\hline POACEAE & Bromus catharticus Vahl \\
\hline POACEAE & Calamagrostis viridiflavescens (Poir.) Steud. \\
\hline POACEAE & Chloris argentina (Hack.) Lillo \& Parodi \\
\hline POACEAE & Chloris bahiensis Steud \\
\hline POACEAE & Chloris gayana Kunth \\
\hline POACEAE & Chloris uliginosa Hack. \\
\hline POACEAE & Ctenium brachystachyum (Nees) Kunth \\
\hline POACEAE & Ctenium polystachyum Balansa \\
\hline POACEAE & Cynodon dactylon (L.) Pers. \\
\hline POACEAE & Cynodon dactylon (L.) Pers. var. pilosus Caro \& Sánchez \\
\hline POACEAE & Danthonia montana Doll \\
\hline POACEAE & Danthonia secundiflora J. Preal \\
\hline POACEAE & Deyeuxia viridiflavescens (Poir.) Kunth \\
\hline POACEAE & Digitaria adscendens \\
\hline POACEAE & Digitaria bicornis (Lam.) Roem. \& Schult. \\
\hline POACEAE & Digitaria ciliaris (Retz.) Koeler \\
\hline POACEAE & Digitaria corynotricha (Hack.) Henrard \\
\hline POACEAE & Digitaria eriantha Steud \\
\hline POACEAE & Digitaria insularis (L) Fedde \\
\hline POACEAE & Digitaria phaeothrix (Trin.) Parodi \\
\hline POACEAE & Digitaria purpurea Swallen \\
\hline POACEAE & Digitaria sanguinalis $\mathrm{L}$ \\
\hline POACEAE & Eleusine indica (L.) Gaertn. \\
\hline POACEAE & Eleusine tristachya (Lam.) Lam. \\
\hline POACEAE & Elionurus adustus (Trin.) Ekman \\
\hline POACEAE & Elionurus latiflorus (Nees ex Steud.) Hack. \\
\hline POACEAE & Elionurus muticus (Spreng.) Kunth \\
\hline POACEAE & Eragrostis airoides Nees \\
\hline POACEAE & Eragrostis bahiensis Schrad Ex Sculth \\
\hline POACEAE & Eragrostis leucosticta Nees ex Dool \\
\hline
\end{tabular}


Anexo 1. Continuação...

\begin{tabular}{|c|c|}
\hline Família & Espécie \\
\hline POACEAE & Eragrostis lugens Nees \\
\hline POACEAE & Eragrostis neesii Trin. \\
\hline POACEAE & Eragrostis perennis Doell \\
\hline POACEAE & Eragrostis polytricha Nees \\
\hline POACEAE & Eragrostis seminuda Trin. \\
\hline POACEAE & Erianthus asper Nees \\
\hline POACEAE & Eriochrysis cayennensis P. Beauv. \\
\hline POACEAE & Eustachys caribaea (Spreng.) Herter \\
\hline POACEAE & Eustachys distichophylla (Lag.) Nees (= Chloris distichophylla) \\
\hline POACEAE & Eustachys ulignosa (Hack.) Herter \\
\hline POACEAE & Festuca ampliflora Döll \\
\hline POACEAE & Gymnopogon spicatus (Spreng.) Kunth \\
\hline POACEAE & Heteropogon leptocladus (Hack.) Roberty \\
\hline POACEAE & Heteropogon villosus Nees \\
\hline POACEAE & Holcus lanatus L. \\
\hline POACEAE & Homolepis glutinosa (Sw.) Zuloaga \& Soderstr. \\
\hline POACEAE & Hypogynium virgatum (Desv.) Dandy \\
\hline POACEAE & Ichnanthus bambusiflorus (Trin.) Döll \\
\hline POACEAE & Ichnanthus inconstans Döll \\
\hline POACEAE & Ichnanthus pubescens Swallen \\
\hline POACEAE & Ichnanthus ruprechtii Doell \\
\hline POACEAE & Imperata brasiliensis Trin. \\
\hline POACEAE & Leersia hexandra Sw. \\
\hline POACEAE & Leptocoryphium lanatum (Kunth) Nees \\
\hline POACEAE & Melinis minutiflora $\mathrm{P}$. Beauv \\
\hline POACEAE & Melinis repens (Willd.) G. Zizka (= Rhynchelytrum repens) \\
\hline POACEAE & Merostachys multiramea Hack \\
\hline POACEAE & Mesosetum ferrugineum (Trin.) Chase \\
\hline POACEAE & Otachyrium versicolor (Doel) Henr \\
\hline POACEAE & Panicum cervicatum Chase \\
\hline POACEAE & Panicum cyanescens Ness \\
\hline POACEAE & Panicum decipiens Nees ex Trin \\
\hline POACEAE & Panicum demissum Trin. \\
\hline POACEAE & Panicum ghiesbreghtii E. Fourn. \\
\hline POACEAE & Panicum grumosum Nees \\
\hline POACEAE & Panicum laxum Sw. \\
\hline POACEAE & Panicum millegrana Poir. \\
\hline POACEAE & Panicum olyroides $\mathrm{HBK}$ \\
\hline POACEAE & Panicum olyroides HBK var hirsutum Henrard \\
\hline POACEAE & Panicum proboscideum Trin. \\
\hline POACEAE & Panicum procurrens Nees ex Trin \\
\hline POACEAE & Panicum pseudisachne $\mathrm{Mez}$ \\
\hline POACEAE & Panicum repens $\mathrm{L}$. \\
\hline POACEAE & Panicum rivulare Trin. \\
\hline POACEAE & Panicum rude Nees \\
\hline POACEAE & Panicum sabulorum Lam. \\
\hline POACEAE & Panicum sellowii Nees \\
\hline POACEAE & Panicum stigmosum Trin. \\
\hline POACEAE & Panicum stoloniferum Poir. \\
\hline POACEAE & Panicum superatum Hack \\
\hline POACEAE & Panicum tricholaenoides Steud. \\
\hline POACEAE & Panicum versicolor Doell \\
\hline POACEAE & Paspalum ammodes Trin. \\
\hline POACEAE & Paspalum carinatum Humb. \& Bonpl. ex Flüggé \\
\hline POACEAE & Paspalum carinatum Humb. \& Bonpl. ex Flüggé \\
\hline POACEAE & Paspalum cinereum (Doell) Chase \\
\hline POACEAE & Paspalum compresifolium Swallen \\
\hline POACEAE & Paspalum conjugatum Bergius \\
\hline POACEAE & Paspalum corcovadense Raddi \\
\hline POACEAE & Paspalum cordatum Hack \\
\hline
\end{tabular}


Anexo 1. Continuação...

\begin{tabular}{|c|c|}
\hline Família & Espécie \\
\hline POACEAE & Paspalum dasytrichium Dusén ex Swallen \\
\hline POACEAE & Paspalum dilatatum Poir. \\
\hline POACEAE & Paspalum erianthum Nees ex Trin \\
\hline POACEAE & Paspalum falcatum Nees ex Steud. \\
\hline POACEAE & Paspalum geminiflorum Steud. \\
\hline POACEAE & Paspalum glaucescens Hack. \\
\hline POACEAE & Paspalum hyalinum Nees ex Trin. \\
\hline POACEAE & Paspalum lineare Trin. \\
\hline POACEAE & Paspalum maculosum Trin. \\
\hline POACEAE & Paspalum milegrana Schrades \\
\hline POACEAE & Paspalum notatum Flüggé var. notatum \\
\hline POACEAE & Paspalum paniculatum $\mathrm{L}$. \\
\hline POACEAE & Paspalum parodianum Henrard \\
\hline POACEAE & Paspalum pectinatum Nees \\
\hline POACEAE & Paspalum plicatulum Michx \\
\hline POACEAE & Paspalum polyphyllum Nees ex Trin \\
\hline POACEAE & Paspalum pumilum Nees \\
\hline POACEAE & Paspalum ramboi I.L. Barreto \\
\hline POACEAE & Paspalum repandum Nees \\
\hline POACEAE & Paspalum rojasii Hack. \\
\hline POACEAE & Paspalum splendens Hack \\
\hline POACEAE & Paspalum unispicatum (Scribn. \& Merr.) Nash \\
\hline POACEAE & Paspalum urvillei Steud \\
\hline POACEAE & Paspalum yaguaronense Henr. \\
\hline POACEAE & Pennisetum purpureum Schumach. \\
\hline POACEAE & Piptochaetium montevidense (Spreng.) Parodi \\
\hline POACEAE & Poa lanigera Nees \\
\hline POACEAE & Rhytachne rottboelioides Desv \\
\hline POACEAE & Saccharum asperum (Nees) Kunth \\
\hline POACEAE & Sacciolepis myuros (Lam.) Chase \\
\hline POACEAE & Sacciolepis vilvoides (Trin.) Chase \\
\hline POACEAE & Schyzachyrium condensatum (Kunth) Nees \\
\hline POACEAE & Schizachyrium gracilipes (Hack.) A. Camus \\
\hline POACEAE & Schizachyrium microstachyum (Desv.) Roseng. \\
\hline POACEAE & Schyzachyrium spicatum (Spr.) Herter \\
\hline POACEAE & Schyzachyrium tenerum Nees \\
\hline POACEAE & Setaria geniculata P. Beauv. \\
\hline POACEAE & Setaria globulifera (Steud.) Griseb \\
\hline POACEAE & Setaria gracilis Kunth \\
\hline POACEAE & Setaria parviflora (Poir.) Kerguelen \\
\hline POACEAE & Setaria poiretiana (Schult) Kunth \\
\hline POACEAE & Setaria scabrifolia (Nees) Kunth \\
\hline POACEAE & Setaria sphacelata (Schumach.) Stapf \& C.E. Hubb. Ex M.B. Moss \\
\hline POACEAE & Setaria verticillata (L.) P. Beauv. \\
\hline POACEAE & Setaria vulpiseta (Lam.) Roem. \& Schult. \\
\hline POACEAE & Sorghastrum minarum (Nees) Hutch \\
\hline POACEAE & Sorghastrum parviflorum Hitchc. \& Chase \\
\hline POACEAE & Sorghastrum stipoides (Kunth) Nash \\
\hline POACEAE & Sporobolus camporum Swallen \\
\hline POACEAE & Sporobolus cubensis Hitchc. \\
\hline POACEAE & Sporobolus eximius (Nees ex Trin.) Ekman var. eximius \\
\hline POACEAE & Sporolobus eximius var. latifolius Boechat \& Longhi-Wagner \\
\hline POACEAE & Sporobolus indicus (L.) R. Br. \\
\hline POACEAE & Sporobolus pseudairoides Parodi \\
\hline POACEAE & Steinchisma decipiens (Nees ex Trin) W V Br \\
\hline POACEAE & Trachypogon canescens Nees \\
\hline POACEAE & Trachypogon polymorphus Hack. \\
\hline POACEAE & Trachypogon spicatus (Lf) Kuntze \\
\hline POLYGALACEAE & Bredemeyera floribunda Willd \\
\hline POLYGALACEAE & Monnina cordata Klotzsch ex Hassk. \\
\hline
\end{tabular}


Anexo 1. Continuação...

\begin{tabular}{|c|c|}
\hline Família & Espécie \\
\hline POLYGALACEAE & Monina tristaniana A. St.-Hil. \& Moq \\
\hline POLYGALACEAE & Polygala angulata $\mathrm{DC}$ \\
\hline POLYGALACEAE & Polygala brasiliensis $\mathrm{L}$. \\
\hline POLYGALACEAE & Polygala cyparissiasA. St.-Hil. \& Moq. \\
\hline POLYGALACEAE & Polygala galioides Poir. var. major A.W.Benn. \\
\hline POLYGALACEAE & Polygala glochidiata Kunth \\
\hline POLYGALACEAE & Polygala hebeclada DC \\
\hline POLYGALACEAE & Polygala hygrophila Kunth \\
\hline POLYGALACEAE & Polygala lancifolia A. St.-Hil. \& Moq. \\
\hline POLYGALACEAE & Polygala leucantha A.W. Benn. \\
\hline POLYGALACEAE & Polygala longicaulis Kunth \\
\hline POLYGALACEAE & Polygala lycopodioides Chodat \\
\hline POLYGALACEAE & Polygala molluginifolia A. St.-Hil. \& Moq. \\
\hline POLYGALACEAE & Polygala moquiniana St. Hil. \\
\hline POLYGALACEAE & Polygala pulchella A. St.-Hil. \& Moq. \\
\hline POLYGALACEAE & Polygala pumila Norlind \\
\hline POLYGALACEAE & Polygala sabulosa A.W. Benn. \\
\hline POLYGALACEAE & Polygala stricta St. Hil \\
\hline POLYGALACEAE & Polygala tenuis DC \\
\hline POLYGALACEAE & Polygala timoutoides Chodat \\
\hline POLYGALACEAE & Polygala violacea Vahl \\
\hline POLYGALACEAE & Pteromonnina richardiana (A. St.-Hil.) B. \\
\hline POLYGALACEAE & Securidaca sellowiana Klotzsch \\
\hline POLYGONACEAE & Polygonum hydropiperoides Michx. \\
\hline POLYGONACEAE & Polygonum meisnerianum Cham. \& Schltdl. \\
\hline POLYGONACEAE & Polygonum persicaria $\mathrm{L}$ \\
\hline POLYGONACEAE & Polygonum rubricaule Cham. \\
\hline POLYGONACEAE & Ruprechtia paranensis Pendry \\
\hline POLYPODIACEAE & Cochlidium serrulatum (Sw.) L.E. Bishop \\
\hline POLYPODIACEAE & Polypodium latipes Langsd. \& Fisch. \\
\hline POLYPODIACEAE & Polypodium vacillans Link \\
\hline PORTULACACEAE & Portulaca mucronata Link \\
\hline PORTULACACEAE & Talinum paniculatum \\
\hline PRIMULACEAE & Anagallis filiformis Cham. \& Schltdl \\
\hline PRIMULACEAE & Myrsine coriacea $(\mathrm{Sw}) \mathrm{R}$ Br ex Roent \& Schult \\
\hline PRIMULACEAE & Myrsine ferruginea Ruiz \& Pav. \\
\hline PRIMULACEAE & Myrsine gardneriana DC \\
\hline PRIMULACEAE & Myrsine guianensis (Aubl.) Kuntze \\
\hline PRIMULACEAE & Myrsine lancifolia Mart \\
\hline PRIMULACEAE & Myrsine parvifolia A. DC. \\
\hline PRIMULACEAE & Myrsine umbellata Mart. \\
\hline PROTEACEAE & Euplassa laxiflora (Meisn.) I.M.Johnst. \\
\hline PROTEACEAE & Roupala brasiliensis (OL.) Willd. \\
\hline PROTEACEAE & Roupala montana Aubl \\
\hline PTERIDACEAE & Adiantopsis chlorophylla (Sw.) Fée \\
\hline PTERIDACEAE & Adiantum raddianum C.Presl. \\
\hline PTERIDACEAE & Doryopteris concolor (Langsd. \& Fisch.) Kuhn \\
\hline PTERIDACEAE & Doryopteris crenulans (Fée) C. Chr. \\
\hline PTERIDACEAE & Doryopteris lomariaceae Klotzsch. \\
\hline PTERIDACEAE & Pteris lechleri Mett. \\
\hline PTERIDACEAE & Pteris vittata $\mathrm{L}$. \\
\hline RHAMNACEAE & Crumenaria polygaloides Reissek \\
\hline RHAMNACEAE & Rhamnus polymorpha \\
\hline RHAMNACEAE & Rhamnus sphaerosperma Sw. \\
\hline ROSACEAE & Prunus myrtifolia (Thunb.) Lindl. \\
\hline ROSACEAE & Rubus brasiliensis Mart \\
\hline RUBIACEAE & Alibertia concolor (Cham.) K. Schum. \\
\hline RUBIACEAE & Borreria brachystemonoides Cham. \& Schltdl. \\
\hline RUBIACEAE & Borreria capitata (Ruiz \& Pav.) \\
\hline RUBIACEAE & Borreria paranaensis E.L. Cabral \& Bacigalupo \\
\hline
\end{tabular}


Anexo 1. Continuação...

\begin{tabular}{|c|c|}
\hline Família & Espécie \\
\hline RUBIACEAE & Borreria paulista E L Cabral \& Bacigalupo \\
\hline RUBIACEAE & Borreria tenella (Kunth) Cham. \& Schltdl. \\
\hline RUBIACEAE & Borreria verticillata $\mathrm{G}$. Mey \\
\hline RUBIACEAE & Coccocypcilum condalia Pers \\
\hline RUBIACEAE & Coccocypcilum guianensis (Aube) \\
\hline RUBIACEAE & Coccocypselum hoehnei Standl \\
\hline RUBIACEAE & Coccocypselum lanceolatum (Ruiz \& Pav.)Pers. \\
\hline RUBIACEAE & Coccocypselum pedunculare Cham. \& Schltdl. \\
\hline RUBIACEAE & Cordiera concolor (Cham.) O. Huntz var concolor \\
\hline RUBIACEAE & Coussarea contracta (Walp.) Müll. Arg. \\
\hline RUBIACEAE & Coutarea hexandra (Jacq) K. Schum \\
\hline RUBIACEAE & Declieuxia cordigera var. divergentiflora (Pohl ex DC) Kirk. \\
\hline RUBIACEAE & Declieuxia cordigera var. angustifolia Mull. Arg \\
\hline RUBIACEAE & Declieuxia dusenii Standl. \\
\hline RUBIACEAE & Declieuxia fruticosa (Willd. ex Roem. \& Schult.) Kuntze \\
\hline RUBIACEAE & Declieuxia lysimachioides Zucc. \\
\hline RUBIACEAE & Declieuxia mucronulata Mart. \\
\hline RUBIACEAE & Diodia alata Nees ex Mart \\
\hline RUBIACEAE & Diodia microcarpa K. Schum. ex Glaz. \\
\hline RUBIACEAE & Emmeorhiza umbellata (Spreng.) K. Schum. \\
\hline RUBIACEAE & Galianthe brasiliensis (Spreng.) E.L. Cabral \&Bacigalupo \\
\hline RUBIACEAE & Galianthe chodatiana (Standl.) E.L. Cabral \\
\hline RUBIACEAE & Galianthe elegans E.L. Cabral \\
\hline RUBIACEAE & Galianthe fastigiata Griseb. \\
\hline RUBIACEAE & Galianthe verbenoides (Cham \& Schltdl) Griseb \\
\hline RUBIACEAE & Galianthe valerianoides (Cham. \& Schltdl.) E.L.Cabral \\
\hline RUBIACEAE & Galium hypocarpium (L.) Endl. ex Griseb. \\
\hline RUBIACEAE & Galium megapotamicum Spreng. \\
\hline RUBIACEAE & Guettarda uruguensis \\
\hline RUBIACEAE & Ixora venulosa Benth. \\
\hline RUBIACEAE & Manettia cordifolia Mart. \\
\hline RUBIACEAE & Manettia ignita K. Schum \\
\hline RUBIACEAE & Mitracarpus hirtus (L.) DC. \\
\hline RUBIACEAE & Oldenlandia thesiifolia (Saint-Hilaire) K.Schum. \\
\hline RUBIACEAE & Palicourea marcgravii A. St.-Hil \\
\hline RUBIACEAE & Palicourea rigida H.B.K. \\
\hline RUBIACEAE & Posoqueria latifolia (Rudge) Roem \& Schult. \\
\hline RUBIACEAE & Psychotria carthagenensis Jacq \\
\hline RUBIACEAE & Psychotria leiocarpa C. et S. \\
\hline RUBIACEAE & Psychotria stachyoides Benth. \\
\hline RUBIACEAE & Psychotria velloziana Benth \\
\hline RUBIACEAE & Richardia acutifolia Standl. \\
\hline RUBIACEAE & Richardia brasiliensis Gomes \\
\hline RUBIACEAE & Richardia pedicellata (K.Schum.) O. Kuntze \\
\hline RUBIACEAE & Richardia stellaris (Cham. \& Schltdl.) Steud. \\
\hline RUBIACEAE & Spermacoce poaya A. St.-Hil. (=Borreria poaya) \\
\hline RUBIACEAE & Spermacoce capitata Ruiz \& Pav. \\
\hline RUBIACEAE & Spermacoce suaveolens $G$. Mey. $(=$ Borreria suaveolens $)$ \\
\hline RUBIACEAE & Spermacoce verticillata $\mathrm{L}$. \\
\hline RUTACEAE & Esenbeckia grandiflora (A. St.-Hil.) Engl. \\
\hline RUTACEAE & Zanthoxylum rhoifolium Lam. \\
\hline SALICACEAE & Casearia decandra Jacq. \\
\hline SALICACEAE & Casearia lasiophylla Eichler \\
\hline SALICACEAE & Casearia obliqua Spr. \\
\hline SALICACEAE & Casearia sylvestris $\mathrm{Sw}$ \\
\hline SANTALACEAE & Phoradendron bathyoryctum Eichler \\
\hline SANTALACEAE & Phoradendron crassifolium (Pohl ex DC.) Eichler \\
\hline SANTALACEAE & Phoradendron harleyi Kuijt \\
\hline SANTALACEAE & Phoradendron liga (Gill. ex Hook. \& Arn.) Eichler \\
\hline SANTALACEAE & Phoradendron undulatum (Pohl ex DC.) Eichler \\
\hline
\end{tabular}


Anexo 1. Continuação...

\begin{tabular}{|c|c|}
\hline Família & Espécie \\
\hline SANTALACEAE & Thesium aphyllum Mart. ex DC. \\
\hline SAPINDACEAE & Cupania vernalis \\
\hline SAPINDACEAE & Matayba elaeagnoides Radlk. \\
\hline SAPINDACEAE & Paullinia elegans Cambess \\
\hline SAPINDACEAE & Serjania caracasana (Jacq) Willd. \\
\hline SAPINDACEAE & Serjania communis Cambess \\
\hline SAPINDACEAE & Serjania erecta Radkl \\
\hline SAPINDACEAE & Serjania glutinosa Radlk. \\
\hline SAPINDACEAE & Serjania gracilis Radlk. \\
\hline SAPINDACEAE & Serjania reticulata Cambess \\
\hline SAPOTACEAE & Chrysophyllum marginatum (Hook. \& Arn.) Radlk. var. marginatum \\
\hline SAPOTACEAE & Pradosia brevipes (Pierre) T.D.Penn \\
\hline SCROPHULARIACEAE & Buddleja brasiliensis Jacq. ex Spreng \\
\hline SCROPHULARIACEAE & Buddleja campestris (Velloso) Walp. \\
\hline SCROPHULARIACEAE & Buddleja elegans Cham. \& Schltdl. \\
\hline SCROPHULARIACEAE & Esterhazya nervosa Benth. \\
\hline SCROPHULARIACEAE & Esterhazya splendida Mikan \\
\hline SELAGINELLACEAE & Selaginella decomposita Spring \\
\hline SELAGINELLACEAE & Selaginella flexuosa Spring \\
\hline SELAGINELLACEAE & Selaginella marginata (Humb. \& Bonpl. ex Willd.) Spring \\
\hline SELAGINELLACEAE & Selaginella muscosa Spr. \\
\hline SMILACACEAE & Smilax brasiliensis Spreng. \\
\hline SMILACACEAE & Smilax campestris Griseb \\
\hline SMILACACEAE & Smilax elastica Griseb \\
\hline SMILACACEAE & Smilax spinosa Mill \\
\hline SMILACACEAE & Smilax staminea Griseb \\
\hline SOLANACEAE & Calibrachoa dusenii (R.E. Fr.) Stehmann \&Semir \\
\hline SOLANACEAE & Calibrachoa ericaefolia (R E Fries) Wijsman \\
\hline SOLANACEAE & Calibrachoa paranaensis (Dusén) Wijsman \\
\hline SOLANACEAE & Cyphomandra divaricata (Mart.) Sendtn. \\
\hline SOLANACEAE & Markea longipes (Sendtn.) Cuatrec. \\
\hline SOLANACEAE & Nicotiana langsdorffii Weinmann \\
\hline SOLANACEAE & Petunia regnellii R.E. Fries \\
\hline SOLANACEAE & Petunia rupestris Dusén \\
\hline SOLANACEAE & Solanum aculeatissimum Jacq. \\
\hline SOLANACEAE & Solanum americanum Mill \\
\hline SOLANACEAE & Solanum argenteum Dunal \\
\hline SOLANACEAE & Solanum boerhaaviifolium Sendtn. \\
\hline SOLANACEAE & Solanum lacerdae Dusen \\
\hline SOLANACEAE & Solanum lycocarpum St Hil \\
\hline SOLANACEAE & Solanum reitzii L.B. Sm. \& Downs \\
\hline SOLANACEAE & Solanum sisymbrifolium Lam \\
\hline STYRACACEAE & Styrax ferrugineus Nees ex Mart \\
\hline STYRACACEAE & Styrax leprosus Hook \& Am \\
\hline SYMPLOCACEAE & Symplocos celastrinea Mart. ex Miq. \\
\hline SYMPLOCACEAE & Symplocos lanceolata (Mart.) A. DC. \\
\hline SYMPLOCACEAE & Symplocos linearifolia \\
\hline SYMPLOCACEAE & Symplocos pentandra Occhioni \\
\hline SYMPLOCACEAE & Symplocos pubescens Klotzsch ex Benth. \\
\hline SYMPLOCACEAE & Symplocos tenuifolia Brand \\
\hline SYMPLOCACEAE & Symplocos uniflora \\
\hline THEACEAE & Gordonia fruticosa (Schrad.) H. Keng \\
\hline THYMELAEACEAE & Daphnopsis fasciculata (Meim.) Nevling \\
\hline THYMELAEACEAE & Daphnopsis racemosa Griseb \\
\hline URTICACEAE & Boehmeria caudata $\mathrm{Sw}$. \\
\hline URTICACEAE & Cecropia pachystachya Trecul. \\
\hline VELLOZIACEAE & Barbacenia paranaensis L.B. Smith \\
\hline VERBENACEAE & Aloysia virgata (Ruiz \& Pav.) Juss. \\
\hline VERBENACEAE & Lantana brasiliensis Link \\
\hline VERBENACEAE & Lantana camara $\mathrm{L}$ \\
\hline
\end{tabular}


Anexo 1. Continuação...

\begin{tabular}{|c|c|}
\hline Família & Espécie \\
\hline VERBENACEAE & Lantana fucata Lindl. \\
\hline VERBENACEAE & Lantana procurrens Schauer \\
\hline VERBENACEAE & Lantana trifolia Cham. \\
\hline VERBENACEAE & Lippia arechavaletae Moldenke \\
\hline VERBENACEAE & Lippia campestris Moldenke \\
\hline VERBENACEAE & Lippia hirta (Cham.) Schauer \\
\hline VERBENACEAE & Lippia intermedia var. parvifolia Moldenke \\
\hline VERBENACEAE & Lippia lupulina Cham. \\
\hline VERBENACEAE & Lippia obscura Briq. \\
\hline VERBENACEAE & Lippia turnerifolia Cham. \\
\hline VERBENACEAE & Stachytarpheta cayenensis (Rich.) Vahl \\
\hline VERBENACEAE & Stachytarpheta dichotoma Ruiz \& Pav. Vahl \\
\hline VERBENACEAE & Stachytarpheta polyura Schauer \\
\hline VERBENACEAE & Verbena balansae Briq. \\
\hline VERBENACEAE & Verbena ephedroides Cham. \\
\hline VERBENACEAE & Verbena hirta Spr \\
\hline VERBENACEAE & Verbena hirta var. gracilis Dusén \\
\hline VERBENACEAE & Verbena humifusa Cham. \\
\hline VERBENACEAE & Verbena lindmanii Briq. \\
\hline VERBENACEAE & Verbena marrubioides Cham. \\
\hline VERBENACEAE & Verbena minutiflora Briquet ex Moldenke \\
\hline VERBENACEAE & Verbena rigida Schauer \\
\hline VERBENACEAE & Verbena strigosa Cham. \\
\hline VERBENACEAE & Verbena tessmannii Moldenke \\
\hline VERBENACEAE & Verbena thymoides Cham. \\
\hline VERBENACEAE & Vitex polygama Cham. \\
\hline VIOLACEAE & Hybanthus parviflorus (Mutis ex L. f.) Baill. \\
\hline VIOLACEAE & Hybanthus velutinus Schulze-Menz \\
\hline VIVIANIACEAE & Viviania rubriflora $\mathrm{R}$. Knuth \\
\hline VOCHYSIACEAE & Callisthene major Mart. \\
\hline VOCHYSIACEAE & Qualea cordata Spreng var cordata \\
\hline VOCHYSIACEAE & Qualea densiflora Warm. \\
\hline VOCHYSIACEAE & Qualea grandiflora Mart. \\
\hline VOCHYSIACEAE & Qualea multiflora Mart. \\
\hline VOCHYSIACEAE & Vochysia magnifica Warm. \\
\hline VOCHYSIACEAE & Vochysia tucanorum Mart \\
\hline WINTERACEAE & Drimys brasiliensis Miers \\
\hline XYRIDACEAE & Xyris capensis Thunb. \\
\hline XYRIDACEAE & Xyris caroliniana Walter \\
\hline XYRIDACEAE & Xyris jupicai Rich \\
\hline XYRIDACEAE & Xyris savanensis Miq. \\
\hline XYRIDACEAE & Xyris schizachne Mart. \\
\hline XYRIDACEAE & Xyris sororia Kunth \\
\hline XYRIDACEAE & Xyris tenella Kunth \\
\hline XYRIDACEAE & Xyris tortula Mart. \\
\hline
\end{tabular}

